DOI: $10.1002 /(($ please add manuscript number))

Article type: Full paper

\title{
Correlative Light-Electron Microscopy shows RGD-targeted ZnO Nanoparticles Dissolve in the Intracellular Environment of Triple Negative Breast Cancer Cells and Cause Apoptosis with Intra-Tumor Heterogeneity.
}

Basmah A. Othman ${ }^{1}$, Christina Greenwood ${ }^{2}$, Ayman F. Abuelela ${ }^{3}$, Anil A. Bharath ${ }^{4}$, Shu Chen ${ }^{1}$, Ioannis Theodorou', Trevor Douglas, ${ }^{5}$, Maskai Uchida, Mary Ryan', Jasmeen S. Merzaban*', Alexandra E. Porter ${ }^{1 *}$.

1. Department of Materials, Imperial College London, Royal School of Mines, Exhibition Road, London, UK SW7 2AZ.

2. Cell and Molecular Biology Research Laboratory, Faculty of Medical Sciences, Post Graduate Medical Institute, Anglia Ruskin University, Bishop Hall Lane, Chelmsford, UK CM1 1SQ.

3. Cell Migration and Signaling Laboratory, Division of Biological and Environmental Sciences and Engineering, King Abdullah University of Science and Engineering (KAUST), Thuwal, Saudi Arabia 239556900.

4. Department of Bioengineering, Imperial College London, Royal School of Mines, Exhibition Road, London, UK SW7 2AZ.

5. Department of Chemistry, Indiana University, 800 E. Kirkwood Avenue, Bloomington, IN, USA 47405.

Address Correspondence to:

* Division of Biological and Environmental Sciences and Engineering, King Abdullah University of Science and Technology (KAUST), Thuwal 23955-6900, Saudi Arabia, +966 (0)12 8082383, jasmeen.merzaban@kaust.edu.sa

F Imperial College London and London Centre for Nanotechnology, London, UK, +44 (0) 2075949691 , a.porter@imperial.ac.uk

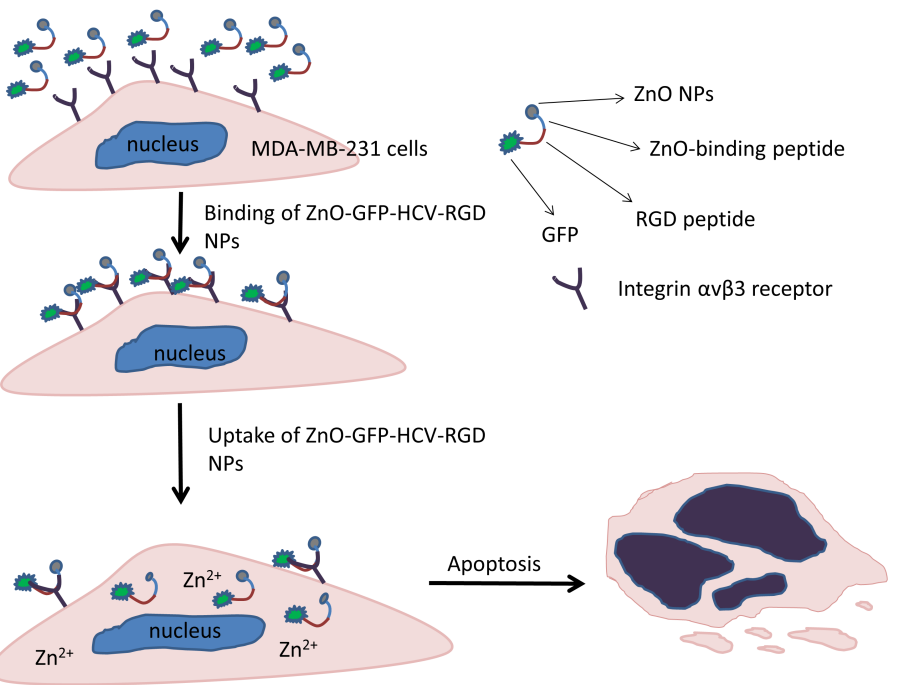

Schematic of binding of ZnO-GFP-HCV-RGD NPs to integrin $\alpha v \beta 3$ receptors, cellular uptake, and induced apoptosis in MDAMB-231 cells.

Abstract ZnO nanoparticles (NPs) are reported to show a high degree of cancer cell selectivity with potential use in cancer imaging and therapy. Questions remain about the mode by which 


\section{WILEY-VCH}

the ZnO NPs cause cell death, whether they exert an intra- or extra-cellular effect, and the resistance among different cancer cell types to $\mathrm{ZnO} \mathrm{NP}$ exposure. The present study quantified the variability between the cellular toxicity, dynamics of cellular uptake and dissolution of bare and RGD (Arg-Gly-Asp)-targeted ZnO NPs by MDA-MB-231 cells. Compared to bare $\mathrm{ZnO} N P s$, RGD-targeting of the ZnO NPs to integrin $\alpha \mathrm{v} \beta 3$ receptors expressed on MDA-MB-231 cells appeared to increase the toxicity of the ZnO NPs to breast cancer cells at lower doses. Confocal microscopy of live MDA-MB-231 cells confirmed uptake of both classes of $\mathrm{ZnO}$ NPs with a commensurate rise in intracellular $\mathrm{Zn}^{2+}$ concentration prior to cell death. The response of the cells within the population to intracellular $\mathrm{Zn}^{2+}$ was highly heterogeneous. In addition, the results emphasize the utility of dynamic and quantitative imaging in understanding cell uptake and processing of targeted therapeutic ZnO NPs at the cellular level by heterogeneous cancer cell populations, which could be crucial for the development of optimized treatment strategies.

Keywords; triple negative breast cancer cells, zinc oxide nanoparticles, cytotoxicity, cellular targeting, integrin $\alpha v \beta 3$ receptors

\section{Introduction}

Breast cancer is a complex and heterogeneous disease that can be classified according to the presence of predictive markers like estrogen receptor (ER), progesterone receptor (PR) and human epidermal growth factor receptor 2 (HER2) [1, 2]. Over $70 \%$ of breast cancers express ER and $15 \%$ overexpress HER2, therefore endocrine and anti-HER2 therapies are key strategies in their management [2]. In approximately $15-20 \%$ of patients with breast cancer, the tumors do not express ER or PR and do not express HER2; these are called triple-negative breast cancers (TNBCs) [3]. Treatment options of TNBCs are limited because these cells do not respond to hormonal therapy [2, 4]. For this reason, identification of novel, targeted therapies for TNBCs would be of great benefit to patients. 


\section{WILEY-VCH}

$\mathrm{ZnO}$ nanomaterials (NMs) were reported to show a high degree of cancer cell selectivity with potential use in cancer imaging and therapy [5-7]. Kishwar et al. (2010), reported the use of $\mathrm{ZnO}$ nanowires (NWs) in cell-localized photodynamic therapy for breast cancer [8]. Many studies also reported on the use of $\mathrm{ZnO} \mathrm{NMs}$ as drug carriers for chemotherapeutic drugs [9, 10] and in tumor imaging [11]. Zinc is an essential trace element involved in a number of biological processes $[12,13]$; however an increase in the local zinc concentration causes cell death [14]. $\mathrm{Zn}^{2+}$ has many effects on cancer cells, which include alteration in gene expression, reduction in cellular metabolism and induction of apoptosis [15, 16]. The apoptotic effects of zinc suggest that $\mathrm{ZnO}$ NPs can be applied as an anticancer agent and provide a potential target for the development of anti-tumor agents [15]. Even more striking are in vitro observations indicating that ZnO NPs can preferentially destroy ER positive cancer cells with significantly less toxicity against normal cells $[15,17,18]$. However, far less information is available about whether targeted ZnO NPs can target and destroy ER negative cells.

Debate exists around whether $\mathrm{ZnO} \mathrm{NMs}$ are taken up by cancer cells and then dissolve intracellularly, or whether they dissolve in the extracellular matrix releasing ionic zinc which subsequently diffuses into the cells. Some studies show that $\mathrm{ZnO} \mathrm{NMs}$ are internalized by cancer cells and dissolve releasing a local dose of toxic $\mathrm{Zn}^{2+}$ ions [19]. Other studies suggest that $\mathrm{ZnO}$ will dissolve in the lysosomes (pH 5.7) [19, 20], or in the acidic microenvironment ( $\mathrm{pH} \sim 5-6)$ associated with cancer $[16,21]$, whereas they will not dissolve in the microenvironment of healthy cells $(\mathrm{pH}$ 7.2) [16]. This is because $\mathrm{ZnO}$ NMs are very sensitive to dissolution in acidic conditions (according to the Pourbaix diagram (or Eh-pH) of $\mathrm{ZnO}[22])$ i.e. below $\mathrm{pH} 6.7$ at physiological temperature. A study by Muller et al. used zinc sensitive dyes to show that $\mathrm{ZnO}$ dissolution only occurs inside macrophage cells and that raised $\mathrm{Zn}^{2+}$ ion concentrations can be correlated directly to cell death [19]. Gilbert et al. 


\section{WILEY-VCH}

combined high resolution X-ray spectromicroscopy and high elemental sensitivity X-ray microprobe analyses to determine the fate of $\mathrm{ZnO}$ and the less soluble iron-doped $\mathrm{ZnO}$ NPs following exposure to cultures of human bronchial epithelial cells, BEAS-2B [23]. The data suggested that cellular uptake of $\mathrm{ZnO}$ NPs is a mechanism of zinc accumulation; following uptake, $\mathrm{ZnO}$ NPs dissolved completely generating intracellular $\mathrm{Zn}^{2+}$ complexed by molecular ligands [24]. A combination of atomic force microscopy and scanning transmission X-ray microscopy (STXM) were used [24], however being surface imaging techniques they do not probe depth information and should be contrasted with techniques that do provide such information. In TNBCs, direct identification of the chemical format of zinc taken up by cells exposed to $\mathrm{ZnO} \mathrm{NPs}$, and its intracellular fate, has not yet been achieved.

The aim of this study is to image the interaction of bare and ZnO-GFP-HCV-RGD NPs with TNBCs at the cellular level, to assess whether this platform can deliver a high local toxic dose of $\mathrm{Zn}^{2+}$ ions intracellularly to TNBCs and if there is any variability in this response within the cell populations. These interactions and the potency of cell exposure to ZnO NPs are compared to ER ${ }^{+}$MCF-7 cells. The toxic effects of ZnO-GFP-HCV-RGD NPs on TNBCs will be discussed in the context of a pH-triggered release of metal ions within the cell. It is hypothesized that by targeting $\mathrm{ZnO} N P s$ to the integrin $\alpha \mathrm{v} \beta 3$ receptors expressed in TNBCs, the functionalized ZnO NPs can be targeted to cancer cells, specifically killing those cells and leading to a lower therapeutic dose of $\mathrm{ZnO}$ NMs. Since metastatic breast tumors show a 1015 fold higher expression of $\alpha v \beta 3$ receptors than healthy epithelial cells, integrin $\alpha v \beta 3$ was selected as a target [25-27] and RGD peptide was used as a targeting agent. For the first time, uptake and intracellular dissolution and variability of the response of the cells within the cell population of ZnO-GFP-HCV-RGD NPs by TNBCs is correlated to cell death using dynamic confocal imaging. 


\section{WILEY-VCH}

\section{Results}

\subsection{Physicochemical characterization and dissolution of ZnO nanoparticles}

A range of physicochemical properties of bare and ZnO-GFP-HCV-RGD NPs were characterized. Based on product information, bare ZnO NPs have a physical size ranging from 10-30 nm. The dispersion state of bare and functionalized NPs in cell culture medium was investigated by cryo-transmission electron microscopy (Cryo-TEM). This technique allows NP solutions to be frozen rapidly and viewed directly in the frozen state, which makes conventional sample drying process unnecessary, thus NPs can be analyzed close to their natural state in solution, eliminating drying-induced artifacts. Cryo-TEM images show that the bare and the ZnO-GFP-HCV-RGD NPs are near-spherical and form agglomerates of hundreds of nanometers in MEM cell culture media containing $10 \%$ FBS (Figure 1A and B). Indeed, the hydrodynamic sizes of bare and targeted ZnO NPs in MEM with $10 \%$ FBS as characterized by dynamic light scattering (DLS) are $427 \pm 51.00$ and $490.6 \pm 14.56 \mathrm{~nm}$, respectively. The white arrows indicate the formation of protein corona $(50-200 \mathrm{~nm}$ in thickness) around bare $\mathrm{ZnO}$ NPs (Figure 1A, white arrows). However, there was no pronounced protein corona formation around ZnO-GFP-HCV-RGD NPs (Figure 1B). A schematic of the RGD functionalization protein attached to the ZnO NPs is shown in Figure 1C. The protein is composed of a cell targeting peptide domain (CDCRGDCFC), a $\mathrm{ZnO}$ binding peptide domain (HCVAHR) and a green fluorescence protein (GFP) for tracking the modified ZnO NPs by fluorescence microscopy.

Inductively coupled plasma-optical emission spectroscopy (ICP-OES) dissolution measurements of bare $\mathrm{ZnO}$ NPs in different cell culture media used throughout this study, as well as in HEPES confocal imaging buffer $(\mathrm{pH}=7.4)$ and lysosomal simulated body fluid (Lyso-SBF, $\mathrm{pH}=5.2$ ) at $37^{\circ} \mathrm{C}$ are presented in supplementary information, Figure S3A-B. Bare $\mathrm{ZnO}$ NPs showed $\leq 10 \mu \mathrm{g} / \mathrm{ml}$ dissolution in all cell culture media $(\mathrm{pH} \mathrm{7.3)}$ ) and the 


\section{WILEY-VCH}

A

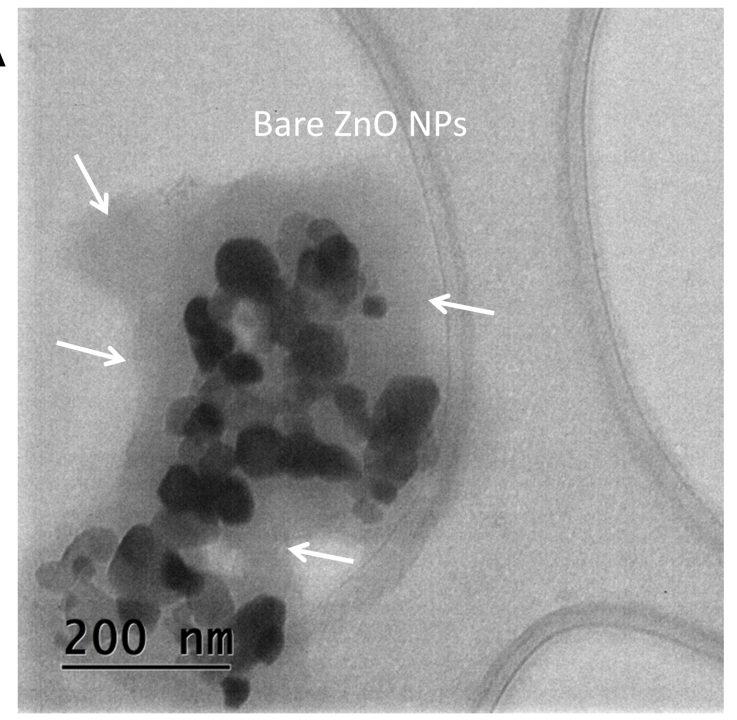

B
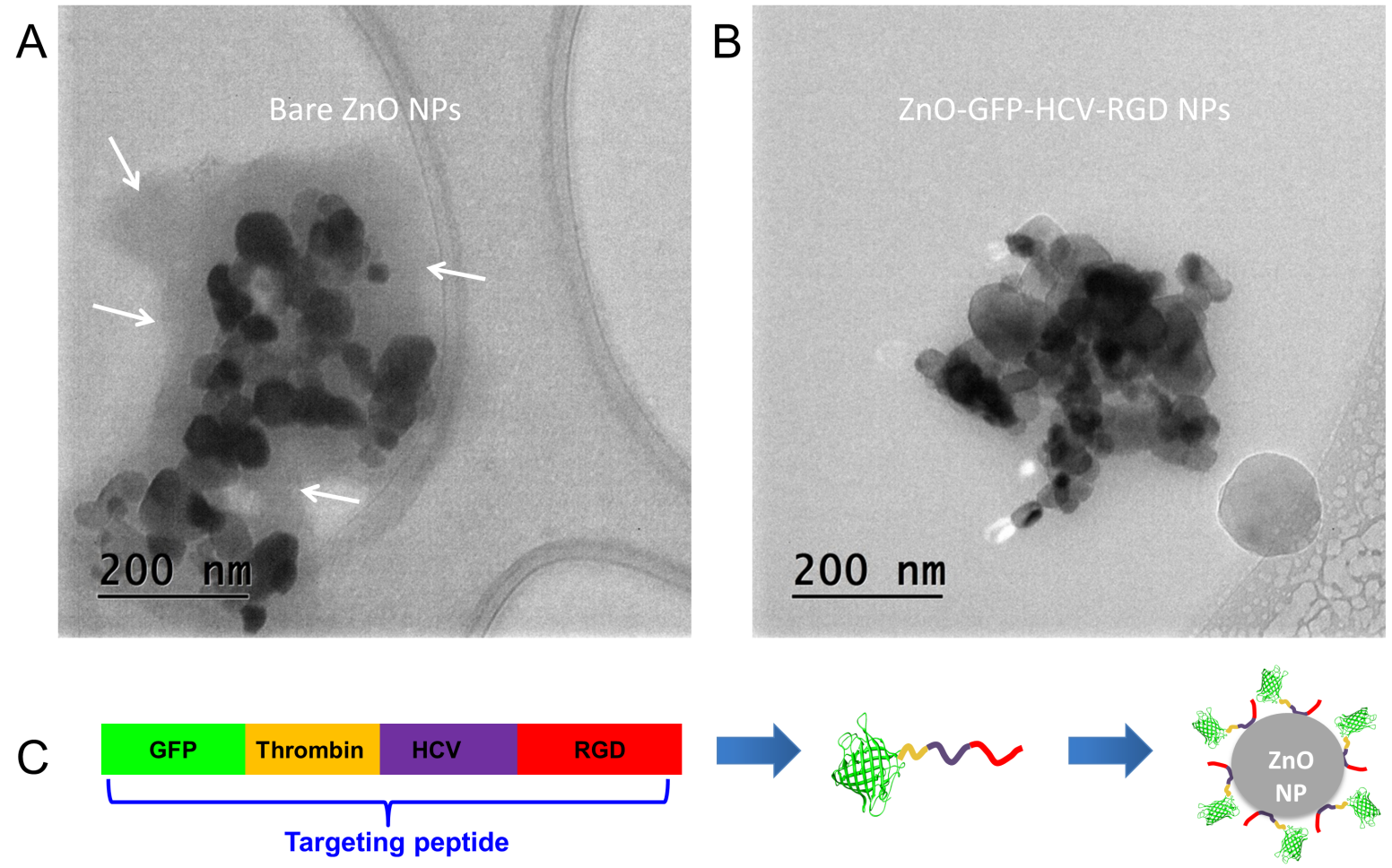

diagram of zinc oxide [22], bare $\mathrm{ZnO}$ NPs completely dissolved (450 $\mu \mathrm{g} / \mathrm{ml})$ in Lyso-SBF $(\mathrm{pH}=5.2)$ (Figure S3B). To assess the effects of the RGD-targeting peptide on the dissolution of the NPs, dissolution of the ZnO-GFP-HCV-RGD NPs (described in Supplementary information, Figure S3C) was studied in HEPES confocal imaging buffer at $\mathrm{pH}$ 7.4. The targeted ZnO-GFP-HCV-RGD NPs experienced a low amount of dissolution $(<1 \mu \mathrm{g} / \mathrm{ml})$ in HEPES confocal imaging buffer (Figure S3C).

Figure 1: Cryo-TEM images of (A) bare ZnO and (B) ZnO-GFP-HCV-RGD NPs. There is pronounced formation of protein corona around bare ZnO NPs as indicated by white arrows. The spherical particle at the bottom right corner in (B) is an ice particle. (C) Simplified schematic of the functionalization peptide attached to the ZnO NPs. The peptide is composed of a targeting peptide (RGD, red) and a $\mathrm{ZnO}$ binding peptide (HCV, purple). To track binding of the targeting peptide to the surface of the bare ZnO NPs, the peptide was tagged with a GFP protein (green) via thrombin cleavage site (yellow). 


\section{WILEY-VCH}

\subsection{ZnO NPs reduce the viability of MCF-7 and MDA-MB-231 breast cancer cells}

In order to assess the effect of $\mathrm{ZnO}$ NPs on the viability of breast tumor cells, MCF-7 and MDA-MB-231 cell lines were chosen as representative cell models in viability assays, as they best reflect the two main subtypes of breast cancer; hormone receptor positive $\left(\mathrm{ER}^{+} / \mathrm{PR}^{+}\right)$and hormone receptor negative, HER2 negative (TNBC) tumors, respectively [28].

The effects of bare ZnO NPs on the viability of both breast cancer cell lines was measured using the Alamar blue (which measures the metabolic activity and viability of the cells) and LDH (which measures leakage of the plasma membrane and cell death) assays (Figure 2A-C). At concentrations of bare ZnO NPs between 20-60 $\mu \mathrm{g} / \mathrm{ml}$, the MDA-MB-231 and the MCF-7 cells showed a dose dependent reduction in viability as measured by the Alamar blue assay (Figure 2A); compared to non-treated controls (100\% viability), the reduction in the viability of the cells was significant $(\mathrm{P}<0.05)$ at concentrations of $30-60$ and 35-60 $\mu \mathrm{g} / \mathrm{ml}$ in the MDA-MB-231 and the MCF-7 cells, respectively (Figure 2A). The cytotoxic potency $\left(\mathrm{IC}_{50}\right)$ of bare $\mathrm{ZnO} \mathrm{NPs}$, reported as the $50 \%$ lethal concentration $[29,30]$ after $24 \mathrm{~h}$ exposure was 30 and $36 \mu \mathrm{g} / \mathrm{ml}$ for the MDA-MB-231 and MCF-7 cells, respectively. The LDH assay, which measures the leakage of the plasma membrane and hence the cytotoxic effects of the NPs, showed that there was a significant difference $(\mathrm{p}<0.05)$ in the LDH release between the MCF-7 and the MDA-MB-231 cells after $24 \mathrm{~h}$ exposure to bare ZnO NPs at concentrations between 20-60 $\mu \mathrm{g} / \mathrm{ml}$ (Figure 2B). Bare ZnO NPs were more toxic to the MCF-7 cells than the MDA-MB-231 cells. Figure 2B shows that, compared to the positive control (1\% Triton X-100), bare ZnO NPs exhibited a significant $(p<0.05)$ dose dependent toxicity to the MCF-7 cells at all tested concentrations after $24 \mathrm{~h}$ exposure. No clear dose dependent toxicity was measured when the MDA-MB-231 cells were exposed to bare $\mathrm{ZnO}$ NPs at all tested concentrations; the toxicity was only significant at $60 \mu \mathrm{g} / \mathrm{ml}$ of the bare $\mathrm{ZnO}$ NPs but with only $<20 \%$ cytotoxic effects (Figure $2 \mathrm{C}$ ) with the 


\section{WILEY-VCH}

LDH assay. The $\mathrm{IC}_{50}$ of bare $\mathrm{ZnO}$ NPs in the MCF-7 cells after $24 \mathrm{~h}$ exposure was $48 \mu \mathrm{g} / \mathrm{ml}$

(Figure 2B). The $\mathrm{IC}_{50}$ could not be determined for the MDA-MB-231 cells, since the bare $\mathrm{ZnO}$ NPs were only toxic to $<25 \%$ of the cells at the highest concentration tested $(60 \mu \mathrm{g} / \mathrm{ml})$

(Figure 2B). Since the maximum release of $\mathrm{LDH}$ was $<20 \%$ in the MDA-MB-231 cells after $24 \mathrm{~h}$ exposure to the bare $\mathrm{ZnO} \mathrm{NPs}$ even at the highest concentration tested $(60 \mu \mathrm{g} / \mathrm{ml})$, a longer incubation time ( $48 \mathrm{~h}$ ) was examined for both cell lines (Figure $2 \mathrm{C}$ ). Indeed, the bare $\mathrm{ZnO}$ NPs induced a higher toxicity to the MCF-7 and the MDA-MB-231 cells after $48 \mathrm{~h}$ compared to $24 \mathrm{~h}$ exposure.
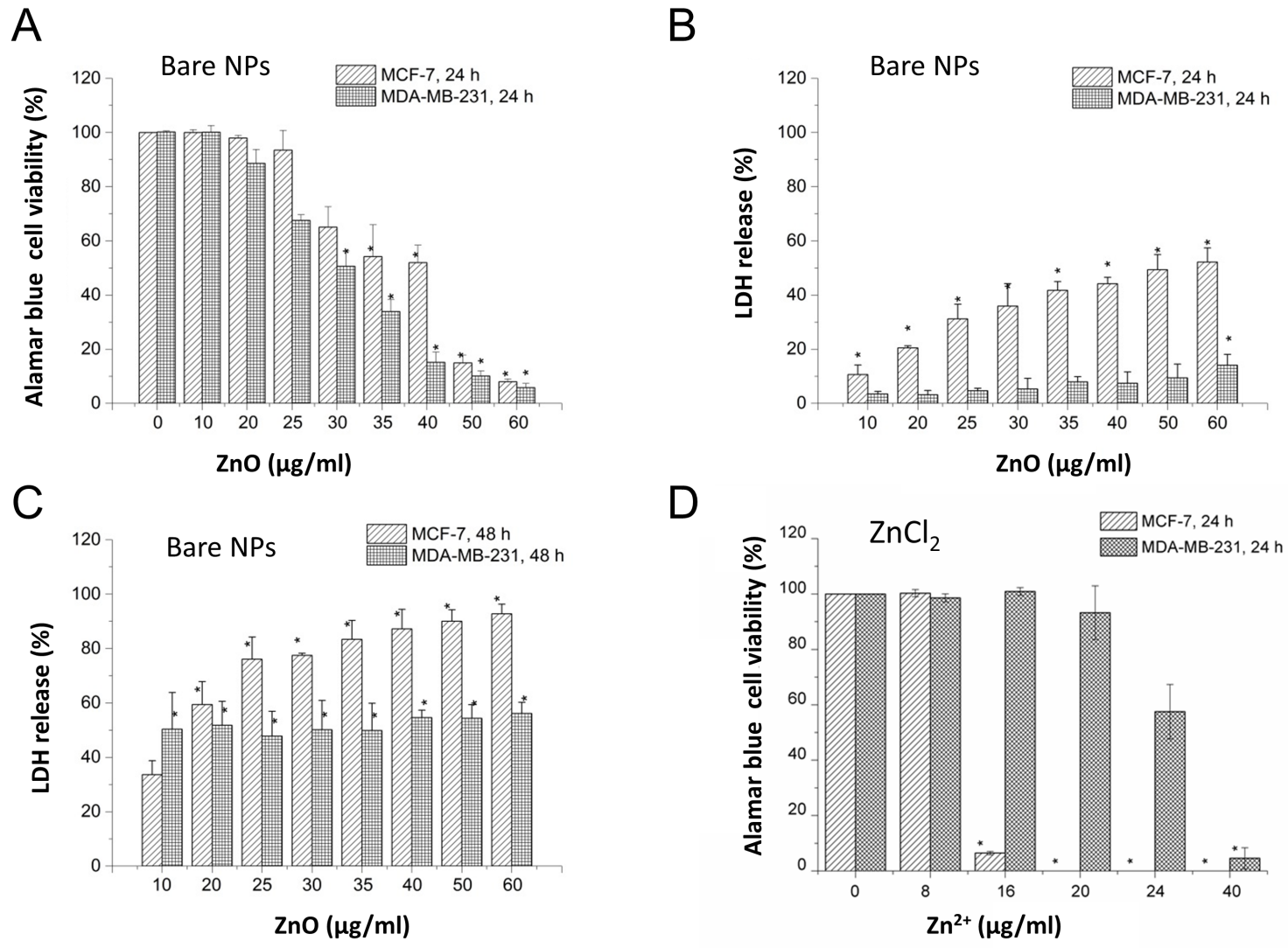

Figure 2: Exposure to bare ZnO NPs reduces viability of MCF-7 and MDA-MB-231 cells. (A) Alamar blue viability assay of MCF-7 and MDA-MB-231 breast cancer cells exposed to bare ZnO NPs for $24 \mathrm{~h}$. (B and C) LDH cytotoxicity assay of MCF-7 and MDA-MB-231 breast cancer cells exposed to bare ZnO NPs for $24 \mathrm{~h}$ and $48 \mathrm{~h}$, respectively. (D) Alamar Blue viability assays of MCF-7 and MDA-MB-231 cells exposed to $\mathrm{Zn}^{2+}(0,8,16,20,24$ and $40 \mu \mathrm{g} / \mathrm{ml}$, equivalent to zinc ions released from $0,10,20,25,30$ and $50 \mu \mathrm{g} / \mathrm{ml}$ of $\mathrm{ZnO}$ ) for $24 \mathrm{~h}$. Cells treated under similar conditions but without $\mathrm{ZnO}$ NPs or $\mathrm{ZnCl}_{2}$ were used as negative controls for the Alamar Blue assay and cells treated with Triton X-100 were used as a positive control for the LDH assay. The values represent the mean \pm STD of three experiments each performed in triplicate. $* \mathrm{p} \leq 0.05$. 


\section{WILEY-VCH}

To evaluate whether the toxic effects of the ZnO NPs were related to a high local dose of $\mathrm{Zn}^{2+}$ ions in the extracellular milieu or an effect of an elevated local dose of $\mathrm{Zn}^{2+}$, the MCF-7 and MDA-MB-231 breast cancer cells were exposed to ionic zinc (Figure 2D). Neither breast cancer cell lines experienced a reduction in their viability after exposure to small doses of ionic zinc $\leq 8 \mu \mathrm{g} / \mathrm{ml}$ for $24 \mathrm{~h}$. At higher concentrations of ionic zinc $(\geq 16$ $\mu \mathrm{g} / \mathrm{ml})$, each cell line experienced a different response; whereas the MCF-7 cells showed a sudden loss in viability at concentrations $\geq 16 \mu \mathrm{g} / \mathrm{ml}$, only a $40 \%$ reduction in the viability of the MDA-MB-231 cells was observed at concentrations as high as $24 \mu \mathrm{g} / \mathrm{ml}$, and a significant loss of the viability ( $>90 \%$ ) was observed only at $40 \mu \mathrm{g} / \mathrm{ml}$ of ionic zinc (Figure 2D). Taken together, these results indicate a difference between the cellular interactions of ionic zinc and particulate $\mathrm{ZnO}$ NPs.

The effect of bare ZnO NPs on the percentage of apoptotic and necrotic population of the breast cancer cells was investigated using flow cytometric analysis of Annexin V/7AAD stained cells (Supplementary information, Figure S4). Overall, exposure of MDA-MB-231 cells to bare ZnO NPs leads to apoptosis while exposure to MCF-7 cells leads to necrosis (Supplementary information, Figure S4).

It was hypothesized that RGD-targeted ZnO NPs may selectively target and destroy the MDA-MB-231 TNBCs and MCF-7 (ER $\left.{ }^{+}, \mathrm{HER} 2^{-}\right)$at lower doses compared to bare $\mathrm{ZnO}$ NPs. The expression of the integrin $\alpha v \beta 3$ receptors in the MCF-7 and MDA-MB-231 cells was investigated (Supplementary information, Figure S5). MDA-MB-231 cells showed an increased expression of the integrin $\alpha v \beta 3$ receptors compared to the MCF-7 cells (Supplementary information, Figure S5). The effect of the targeted ZnO NPs on the viability of both breast cancer cell lines was measured (Supplementary information, Figure S6). The ZnO-GFP-HCV-RGD NPs were toxic to the MCF-7 and MDA-MB-231 cells with an $\mathrm{IC}_{50}$ of $16 \mu \mathrm{g} / \mathrm{ml}$ and $22 \mu \mathrm{g} / \mathrm{ml}$ after $24 \mathrm{~h}$ exposure, respectively (Supplementary information, Figure 


\section{WILEY-VCH}

218 S6). The MCF-7 and MDA-MB-231 cells showed a significant drop in their viability

$219(\mathrm{p}<0.05)$ to $<20 \%$ at 20 and $25 \mu \mathrm{g} / \mathrm{ml}$ of the ZnO-GFP-HCV-RGD NPs, respectively

220 (Supplementary information, Figure S6). The higher sensitivity expressed by the MCF-7 cells

221 to the RGD-targeted ZnO NPs, despite their lower expression of the integrin receptors, could

222 be attributed to the higher sensitivity of the cells to the effects of ionic zinc (refer to Figure 223 2D)

224

\subsection{The targeted ZnO-HCV-RGD-GFP NPs bind to and are taken up by TNBCS}

Treatment of TNBCs is limited and challenging due to a lack of targeted therapy, aggressive behavior and relatively poor prognosis, therefore, using MDA-MB-231 cells as a model, the uptake and dissolution of the ZnO NPs was of key focus in our studies in order to identify novel, targeted therapies for patients. MDA-MB-231 cells showed an increased expression of the integrin $\alpha \mathrm{v} \beta 3$ receptors compared to the MCF-7 cells (Supplementary information, Figure S5), which makes them a prime target for the ZnO-GFP-HCV-RGD NPs. Indeed, MDA-MB231 cells bound ZnO-GFP-HCV-RGD NPs more specifically over the control, ZnO-GFPHCV-GGG NPs (Figure 3).

The preferential ability of RGD-conjugated ZnO-NP to bind MDA-MB-231 cells was determined by various assays. In order to assess the targeting capability of RGD-conjugated NPs, MDA-MB-231 cells were either treated with RGD- or GGG-conjugated ZnO NPs for 30 minutes. A dose as high as $150 \mu \mathrm{g} / \mathrm{ml}$ of the ZnO NPs was used to follow the binding of the NPs within a reasonable time frame. Figure 3A shows a higher binding capacity of RGDconjugated particles compared to GGG-conjugated particles using laser scanning confocal microscopy. Figure 3B shows that the RGD-conjugated NPs tend to form aggregates and bind to the surface of the cells. A closer look at the boundaries of the cells (Figure 3B) shows that the distribution of the particles is heterogeneous around each cell, possibly due to heterogeneity in $\alpha v \beta 3$ expression across the surface of the cell. With the aim of quantifying 


\section{WILEY-VCH}

244 the difference in binding capacity between RGD- and GGG-conjugated NPs, we measured the fluorescence intensity of the area representing a cell and its bound NPs (Figure 3C). Total cell fluorescence (TCF) was measured and the integrated density in the area of one cell and its bound NPs and was corrected to the signal from the background to yield the corrected total cell fluorescence (CTCF). In order to preclude a cell size bias in our calculations, CTCF was divided by cell area (CA). CTCF/CA mean for RGD-treated cells $(3.7 \pm \mathrm{STD}$. deviation=2.2) was 16 times higher than that of GGG-treated cells $(0.22 \pm$ STD. deviation $=0.4)$ with a $95 \%$ confidence interval of $3.45 \pm 1.7(\mathrm{p}<0.001)$. In order to avoid the cell selection bias, integrated density values were measured for 100 equally-sized tiles from RGD and GGG conditions (Figure 3D). A histogram shows the difference in the distribution of the $\log _{10}$ value of integrated densities. Integrated densities were 18.7 higher in RGD condition (mean=31391 \pm STD. deviation=43793) compared to GGG (mean=1675 \pm STD. deviation=2724) with a $95 \%$ confidence interval of $29716 \pm 8709(\mathrm{p}<0.001)$, signifying the greater ability of RGD-conjugated particles to bind MDA-MB-231 cells. Using a fluorometry-based assay, Figure 3E shows the difference in binding capacity of ZnO-GFPHCV-RGD over ZnO-GFP-HCV-GGG NPs to MDA-MB-231 cells from three independent experiments. The mean fluorescence intensity (MFI; $1.90 \pm$ STD. deviation=0.61) for $\mathrm{ZnO}-$ GFP-HCV-RGD-treated cells was 5.18 times higher than that of ZnO-GFP-HCV-GGGtreated cells $(0.37 \pm$ std. deviation $=0.15)$ with a $95 \%$ confidence interval of $1.52 \pm 1.39$ $(p<0.05)$. Finally, flow cytometric analysis (Figure 3F) also revealed that the MFI is over a 3fold higher for cells treated with ZnO-GFP-HCV-RGD NPs over the ZnO-GFP-HCV-GGG control. Overall, these studies unequivocally show the preferential binding of ZnO-GFPHCV-RGD NPs over ZnO-GFP-HCV-GGG NPs to MDA-MB-231 cells. 


\section{WILEY-VCH}
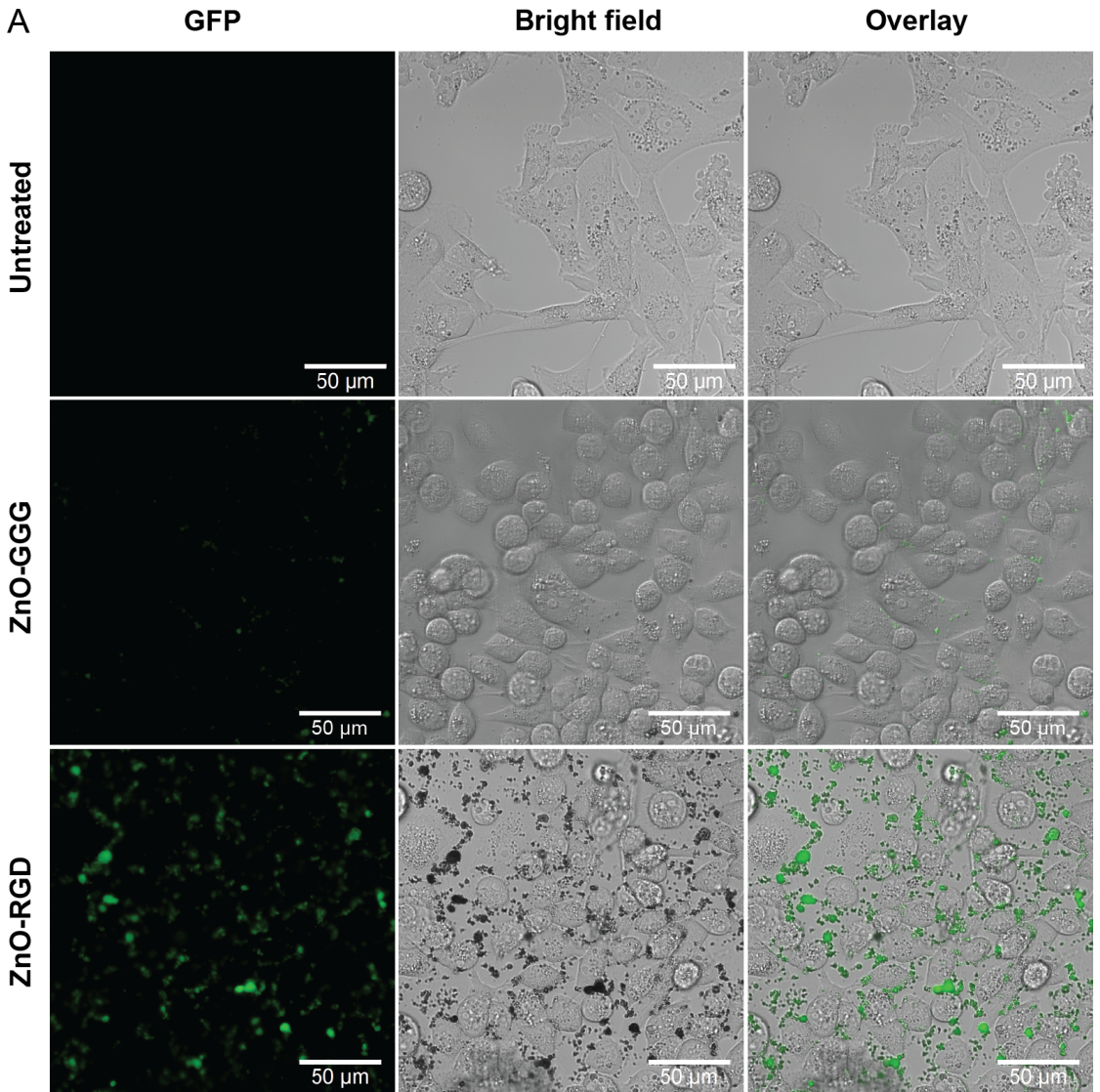

GFP
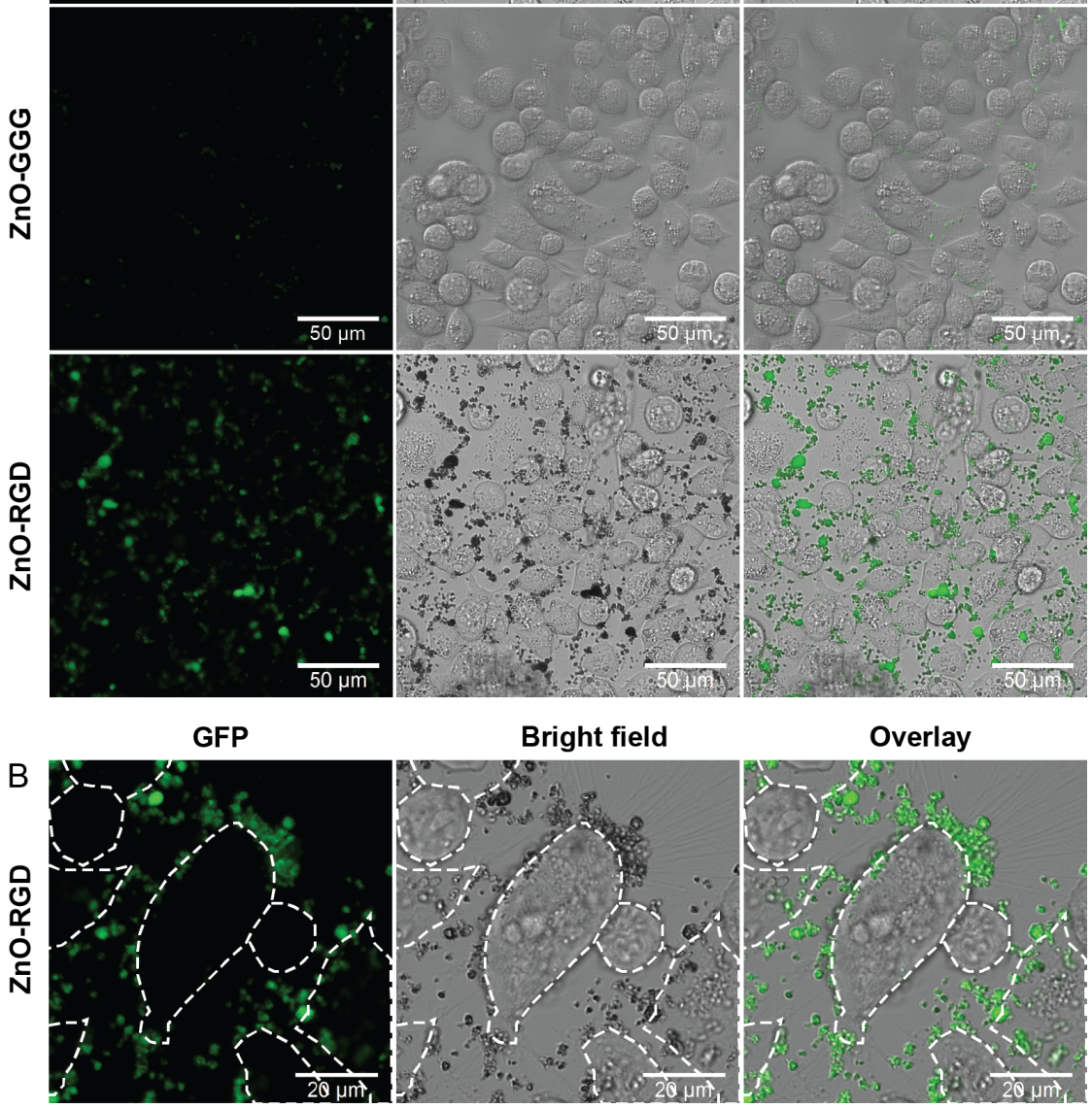

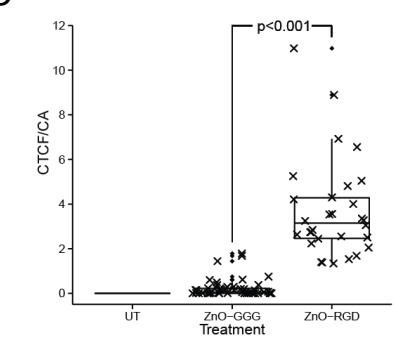

D

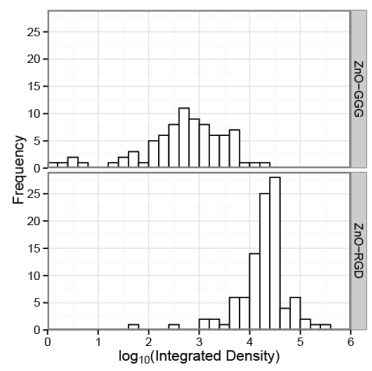

E
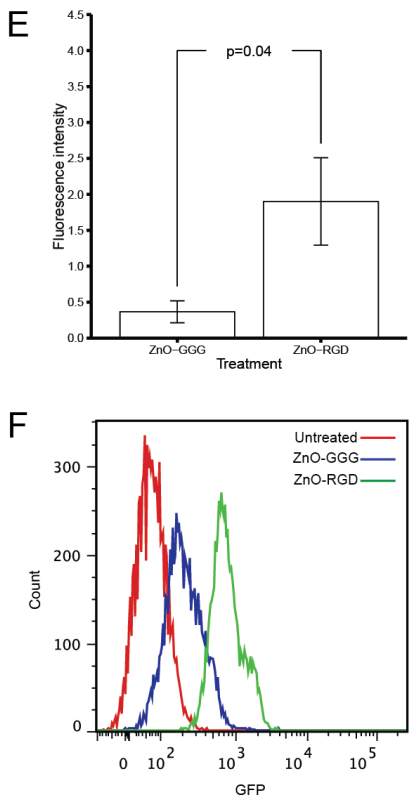

Figure 3: RGD-mediated binding of ZnO-GFP-HCV-RGD NPs to MDA-MB-231 cells. (A) Confocal images of MDAMB-231 cells either left untreated (UT) or treated with $150 \mu \mathrm{g} / \mathrm{mL}$ of ZnO-GFP-HCV-GGG or ZnO-GFP-HCV-RGD NPs for $30 \mathrm{~min}$. The figure shows higher binding capabilities of RGD-coupled NPs compared to GGG-coupled NPs. The figures are representative of $n=3$ independent experiments. (B) Higher magnification confocal images of ZnO-GFP-HCV-RGDtreated cells showing direct binding of ZnO-GFP-HCV-RGD NPs (green) to the surface of MDA-MB-231 cells. Dotted lines represent the boundaries of the cells. (C) Box plot of fluorescence intensity observed in confocal experiments represented in (A) denoted as CTCF/CA (see Methods). Raw values are represented by individual crosses (x). (D) Representative confocal images were divided into 100 tiles and integrated density was calculated. A histogram of $\log _{10}$ (integrated density) shows a positive shift in case of ZnO-GFP-HCV-RGD compared to ZnO-GFP-HCV-GGG. (E) Fluorescence spectroscopy analysis of MDA-MB-231 cells that were either left untreated or treated with ZnO-GFP-HCV-GGG or ZnO-GFP-HCV-RGD particles. The fluorescence signal from untreated cells was used as a blank that was subtracted from the ZnO-GFP-HCVRGD and ZnO-GFP-HCV-GGG samples. Error bars represent the standard deviation of $n=3$ independent experiments. (F) Representative flow cytometric histograms showing the green fluorescence intensity of MDA-MB-231 cells either left untreated or following treatment with ZnO-GFP-HCV-GGG or ZnO-GFP-HCV-RGD NPs. This is a representative histogram of $n=3$ independent experiments. Statistical significance of differences was determined by two-sided unpaired student's $t$ test and significance was defined as $\mathrm{p}<0.05$. For all binding experiments performed here, NPs were incubated with the MDA-MB-231 cells in binding buffer containing $\mathrm{CaCl}_{2}$ at $4{ }^{\circ} \mathrm{C}$. 


\section{WILEY-VCH}

In order to show that, after binding to MDA-MB-231 cells, the ZnO-GFP-HCV-RGD NPs were internalised by, and dissolved inside the TNBCs, TEM images were taken to show the localisation and morphology of the ZnO-GFP-HCV-RGD NPs inside the cells after $3 \mathrm{~h}$ exposure (Figure 4). None of the conventional heavy metal staining processes, like osmium staining, was applied during TEM sample preparation. This compromises the contrast of cell ultrastructure, however, minimises the artificial alteration of the chemistry of particles [31]. Low resolution bright field TEM (BF-TEM) images (Figure 4A-C) show that the particles are internalised by the cells and are found as individual particles (Figure 4A), as well as clusters of particles in endosome/lysosome-like vesicles and the cytoplasm (Figure 4A and B). High angle annular dark field scanning transmission electron microscopy (HAADF-STEM) imaging is a $\mathrm{Z}$ (atomic number)-contrast imaging technique, therefore this method shows local variations in the atomic number within a sample. HAADF-STEM images (Figure 4D) highlight the morphology of $\mathrm{ZnO}$ NPs present in the cytoplasm from the boxed area in Figure 4C, which had partially dissolved. A representative high resolution TEM (HRTEM) image (Figure 4E) of the ZnO NPs labelled by a box in Figure 4D shows crystalline lattice fringes with an interplanar spacing consistent with bulk $\mathrm{ZnO}(011)$ lattice planes (Inorganic Crystal Structure Database, Ref.ICSD82028) (Figure 4E). A STEM-EDX spectrum taken from the particle (area 1 in (D)) further confirms the presence of $\mathrm{Zn}$; the peaks at around 1.0, 8.6 and 9.6 keV correspond to $\mathrm{Zn}(\mathrm{L})$ and $\mathrm{Zn}(\mathrm{K})$ peaks, respectively (Figure 4F, plot 1); while the STEM-EDX spectrum taken from the background (area 2 in (D)) does not show any trace of Zn (Figure 4F, plot 2). 

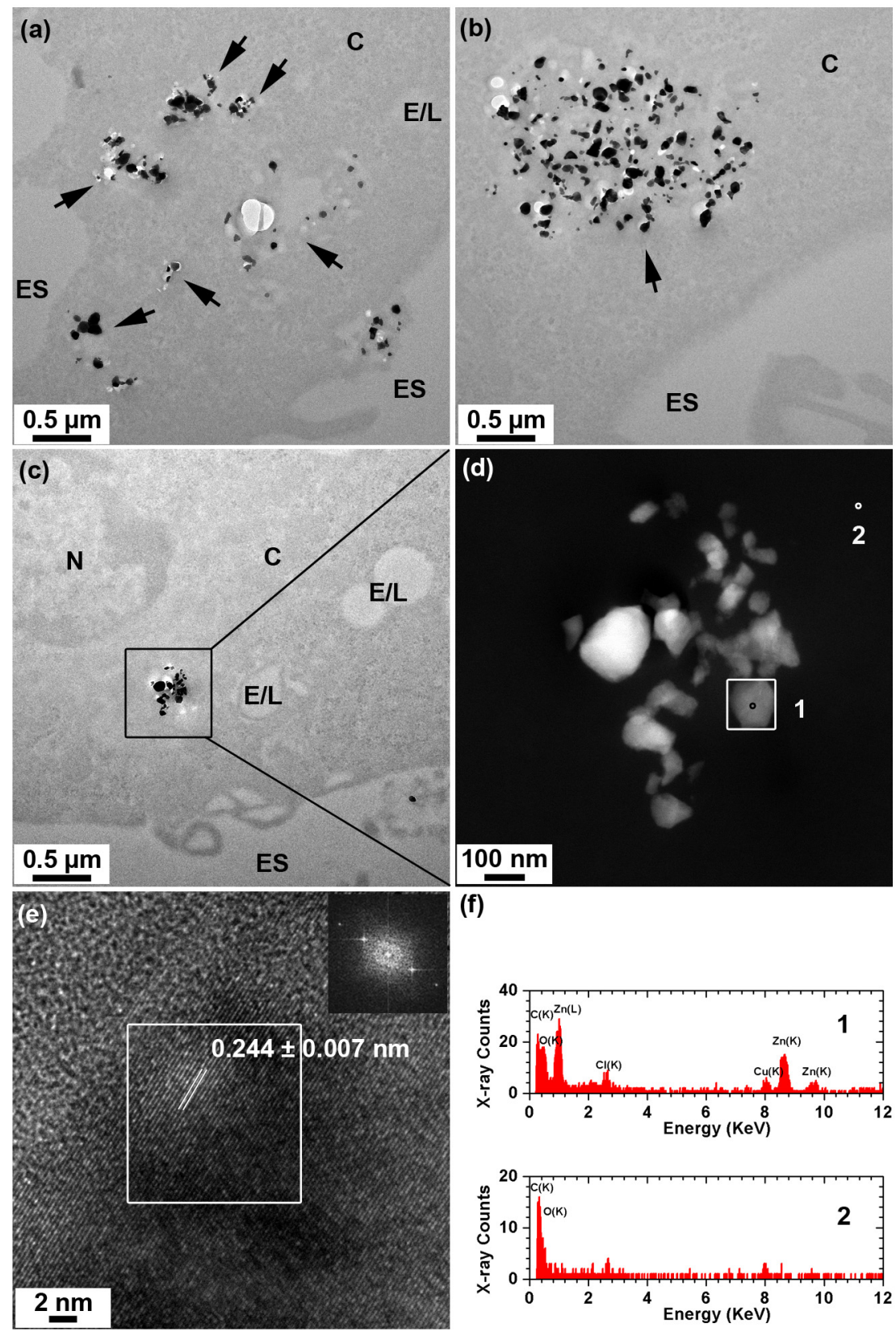

(f)
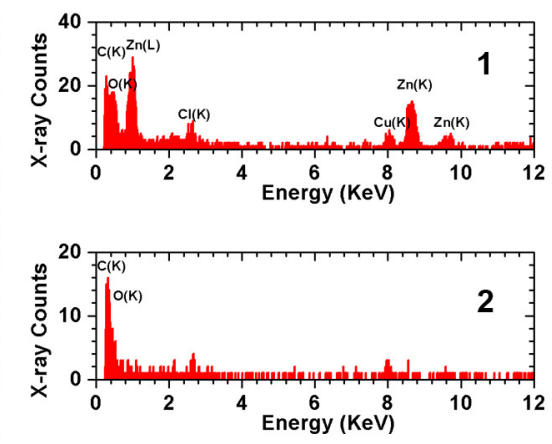

Figure 4: TEM analysis of MDA-MB-231 cells exposed to $30 \mu \mathrm{g} / \mathrm{ml}$ ZnO-GFP-HCV-RGD NPs for $3 \mathrm{~h}$. (A-C) BF-TEM images show the presence of ZnO NPs in endosome/lysosome-like structures (marked by arrows) and the cytoplasm. (D) A HAADFSTEM image highlights the morphology of ZnO NPs, taken from the boxed region in (C). (E) HRTEM shows the crystalline lattice fringes of a NP from the boxed area in (D), the interplanar spacing is consistent with bulk ZnO (011) lattice planes (Inorganic Crystal Structure Database, Ref.ICSD82028). The inset is the FFT pattern taken from the boxed area. (F) STEMEDX spectra ( 1 and 2) taken from the particle and the background (area 1 and area 2 in (D), respectively). The peaks at around 1.0, 8.6 and $9.6 \mathrm{keV}$ in spectrum 1 correspond to $\mathrm{Zn}(\mathrm{L})$ and $\mathrm{Zn}(\mathrm{K})$ peaks, respectively. $\mathrm{ES}=$ extracellular space, $\mathrm{C}=$ cytoplasm, $\mathrm{E} / \mathrm{L}=$ endosome/lysosome and $\mathrm{N}=$ nucleus.

\subsection{Rise of intracellular $\mathrm{Zn}^{2+}$ precedes cell death.}

317 Targeted ZnO NPs. To correlate binding of the ZnO-GFP-HCV-RGD NPs to cells and

318 intracellular ionic $\mathrm{Zn}^{2+}$ release to cell death, we applied dynamic confocal microscopy. For 


\section{WILEY-VCH}

these experiments three different dyes were used to track the NPs, $\mathrm{Zn}^{2+}$ release and cell death, and the heterogeneity of the cell response was quantified (A video of intracellular dissolution of the targeted ZnO-GFP-HCV-RGD NPs by live MDA-MB-231 cells is in Supplementary information; Video 1). To follow the rise of intracellular zinc within a reasonable time frame, a dose as high as $150 \mu \mathrm{g} / \mathrm{ml}$ of the $\mathrm{ZnO}$ NPs was used [32]. Figure 5A-D shows binding of the ZnO-GFP-HCV-RGD NPs (green) to the cell membrane of the MDA-MB-231 cells over time. After $1 \mathrm{~h}$ exposure, the cells were surrounded by a small number of the ZnO-GFPHCV-RGD NPs aggregates (Figure 5A). Over time, significantly more ZnO NPs bound to the cells (Figure 5B and 4C), forming a layer of ZnO-GFP-HCV-RGD NPs surrounding the cells after $4 \mathrm{~h}$ of exposure (Figure 5D). Again, as indicated earlier in Figure 3B, binding of the ZnO-GFP-HCV-RGD NPs to the cell membrane of the MDA-MB-231 cells was heterogeneous (Figure 5D). After binding to the surface of the MDA-MB-231 cells, the ZnOGFP-HCV-RGD NPs dissolved releasing ionic zinc $\left(\mathrm{Zn}^{2+}\right)$ (Figure 5E-H). In some cells, this release of ionic zinc $\left(\mathrm{Zn}^{2+}\right)$ was accompanied by the increase in the intensity of Zinquin (blue) inside the cells, which was clear after $4 \mathrm{~h}$ of exposure (Figure 5F) and the rise in the intracellular zinc correlated to cell death, as indicated by the penetration of PI (red) into the cells and the rise of its intracellular concentration (Figure 5G-H). However, this process was variable within the cell population and in some cells PI release was not preceded by Zinquin release, or occurred at the same time as Zinquin release. Analysis of the cells after exposure to the targeted ZnO-GFP-HCV-RGD showed that $20 \%$ of the cells in the imaging field died as early as $6 \mathrm{~h}$ exposure and almost $80 \%$ of the cells died after $12 \mathrm{~h}$ exposure. Analysis of the confocal data shown in Figure 5 was used to generate representative intensity curves of Zinquin and PI (Figure 6A-B). The intensity curves of Zinquin and PI from the cells exposed to the RGD-targeted ZnO NPs show a gradual increase in Zinquin intensity over time and a sharp increase in PI once a significant concentration of $\mathrm{Zn}^{2+}$ is reached (Figure 6A and B). In 


\section{WILEY-VCH}

contrast, the untreated control MDA-MB-231 cells, imaged under the same conditions, did not show any increase in intracellular zinc throughout the confocal imaging experiments confirming that the $\mathrm{Zn}^{2+}$ indicator did not fluoresce over time, in the absence of zinc (Figure 6C). Figure 6D-E shows representative confocal images of the dissolution of $\mathrm{ZnO}-\mathrm{GFP}$ HCV-RGD ZnO NPs inside MDA-MB-231 cells after 16 and $24 \mathrm{~h}$, respectively 349 (Supplementary information, video 1). 


\section{WILEY-VCH}
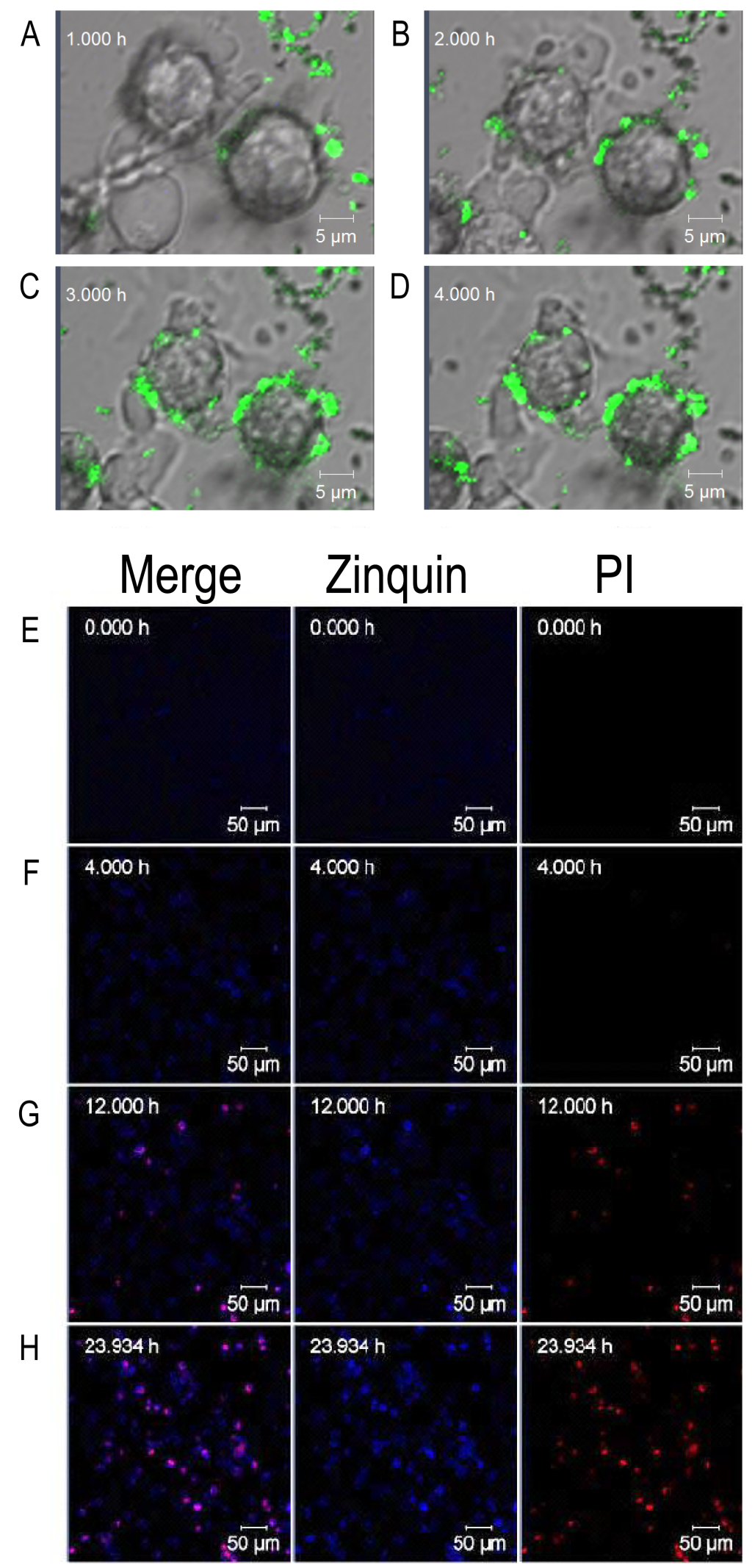

Figure 5: (A-D) Bright field and confocal images of MDA-MB-231 cells exposed to $150 \mu \mathrm{g} / \mathrm{ml} \mathrm{ZnO}-\mathrm{GFP}-\mathrm{HCV}-\mathrm{RGD}$ NPs (green) showing binding of the NPs to the surface of the cell after (A) $1 \mathrm{~h}$, (B) $2 \mathrm{~h}$, (C) $3 \mathrm{~h}$, and (D) $4 \mathrm{~h}$ exposure. (E-H) Confocal images showing MDA-MB-231 cells exposed to $150 \mu \mathrm{g} / \mathrm{ml}$ of the ZnO-GFP-HCV-RGD NPs led to the release of $\mathbf{Z n}^{2+}$ inside the cells over time; (E) $0 \mathrm{~h},(\mathbf{F}) 4 \mathrm{~h}$, (G) $12 \mathrm{~h}$, and (H) $24 \mathrm{~h}$, as indicated by the increase in intensity of the $\mathrm{Zn}^{2+}$ indicator, Zinquin (blue). Toxic levels of $\mathrm{Zn}^{2+}$ ions inside the cell subsequently resulted in cellular penetration of PI (red) indicating the loss in viability and membrane integrity. 


\section{WILEY-VCH}
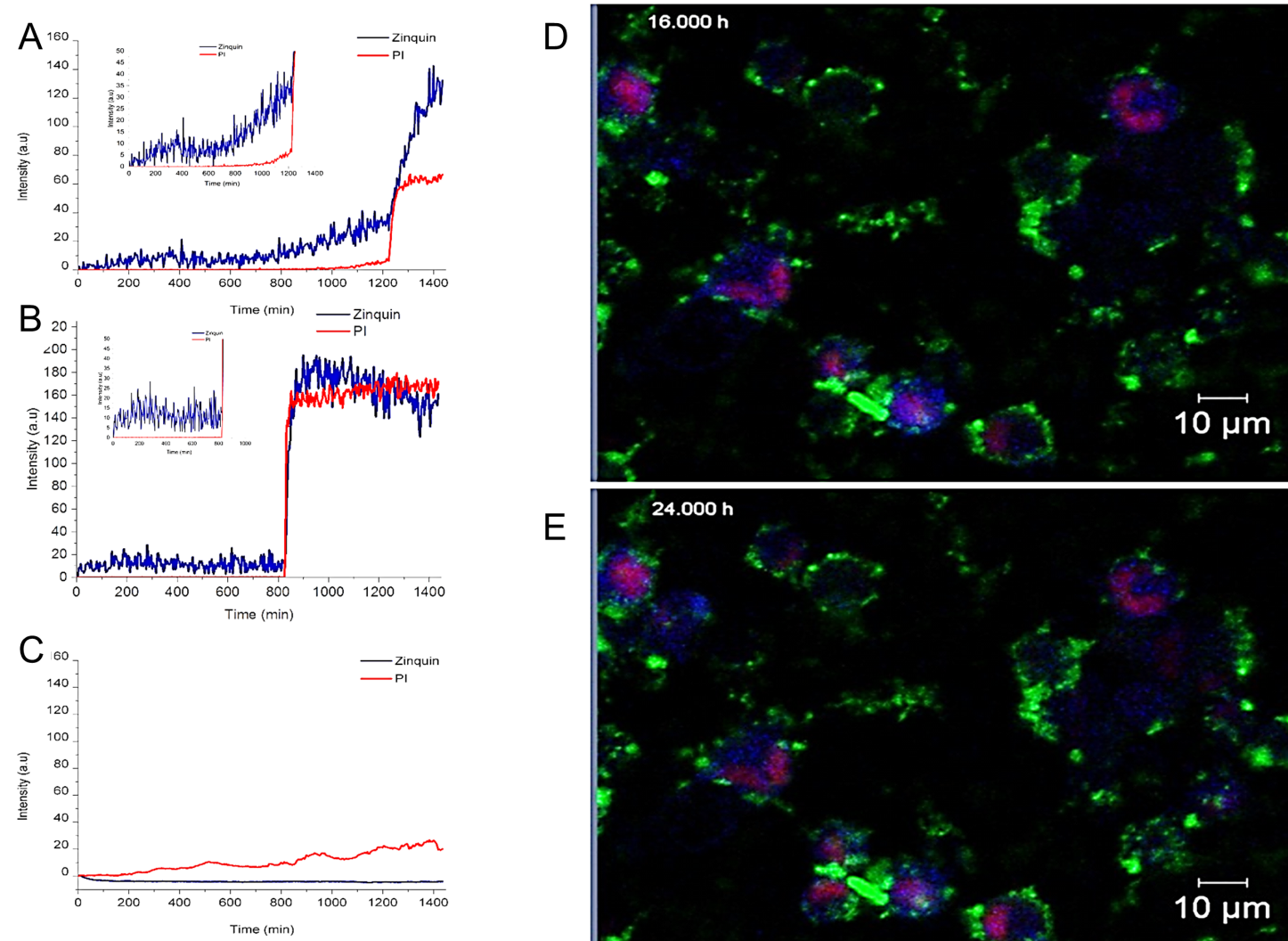

$E$

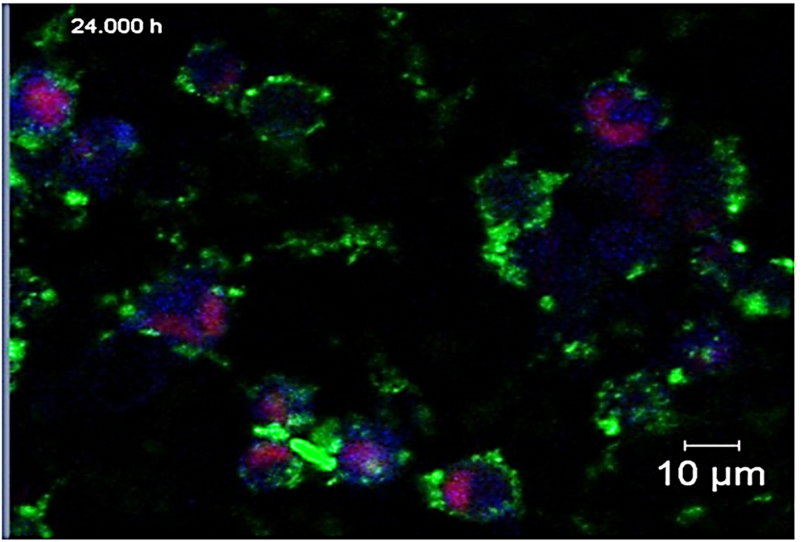

Figure 6: (A-C) Intensity curves of Zinquin and PI in MDA-MB-231 cells after exposure to ZnO-GFP-HCV-RGD NPs showing an increase in intracellular $\mathrm{Zn}^{2+}$ and subsequent cell death. The MDA-MB-231 cells were loaded with the cell-permeant $\mathrm{Zn}^{2+}$ indicator Zinquin-AM prior to incubation with (A and B) $150 \mu \mathrm{g} / \mathrm{ml}$ the targeted NPs, (C) imaging buffer (NA control). The insets in A and B show a gradual increase in Zinquin intensity over time. Fluorescent intensities were measured within a representative region of interest (ROI). (D and E) Confocal images showing dissolution of ZnO-GFPHCV-RGD NPs inside MDA-MB-231 cells after 16 and $24 \mathrm{~h}$, respectively. The ZnO-GFP-HCV-RGD NPs released $\mathrm{Zn}^{2+}$ inside the cells, which was accompanied by the increase in the intensity of Zinquin (blue). Toxic levels of $\mathrm{Zn}^{2+}$ ions inside the cell resulted cellular penetration of PI which stained the nuclei of dead cells red. Zinquin fluoresces blue upon binding ionic zinc $\left(\mathrm{Zn}^{2+}\right)$. Images were acquired over a time course of $24 \mathrm{~h}$.

Cellular heterogeneity is a crucial aspect of population characteristics especially in cancerous cells, which dictates treatment response and resistance issues associated with such heterogeneity [33]. To detect cellular variability in response to ZnO NPs, measurements were made on 10 individual cells using a region tracking algorithm to "follow" the Zinquin and PI intensities at different regions of the cells. Three locations were selected (these are described in Supplementary information, Figure S7) to act as the centers for sampling color channel intensity: a) on the boundary of cells (R1), b) $75 \%$ of the distance between the cell's center and boundary location (R2), c) within the center of a cell (R3). This sampling was used to 


\section{WILEY-VCH}

construct weighted intensity samples from the three regions sampled within each cell. Figure 7 illustrates that the cellular response to the ZnO-GFP-HCV-RGD NPs is highly heterogeneous within the cell population. In fact, Figure 7B, D, E, G, and J showed a lag over time in the position of the ZnO-GFP-HCV-RGD signal (green) at R1 and R2, indicating that the particles are entering the cells. For some cells, there is a slow increase in Zinquin followed by a rapid increase in PI intensities (e.g. Figure 7A and 7D). For most of the other cells, the rate of increase of PI and Zinquin intensities inside the cells is less rapid (Figure 7B-C, and 7E-J). There were regular oscillations in the Zinquin and PI intensities inside the cells; it has been reported that $\mathrm{Zn}^{2+}$ dynamics may modulate $\mathrm{Ca}^{2+}$ signaling [34], and since the PI fluorescence itself relies directly on the amount of $\mathrm{Ca}^{2+}$ in the growth solution [35], oscillations in the PI and Zinquin signaling could occur. The GFP signal was constant in R3 over time, which could indicate dissolution of the ZnO-GFP-HCV-RGD NPs (Figure 7A-J).

The absolute value of correlation coefficient $(|p|)$ between the red and blue illumination signal levels from regions inside and outside of cells showed a highly significant correlation (KS statistic of 0.97) between ionic zinc and PI within cells with no discernible difference in the distributions (KS statistic of 0.03) in regions outside the cells (Figure 8A and $8 \mathrm{~B}$, respectively). 


\section{WILEY-VCH}
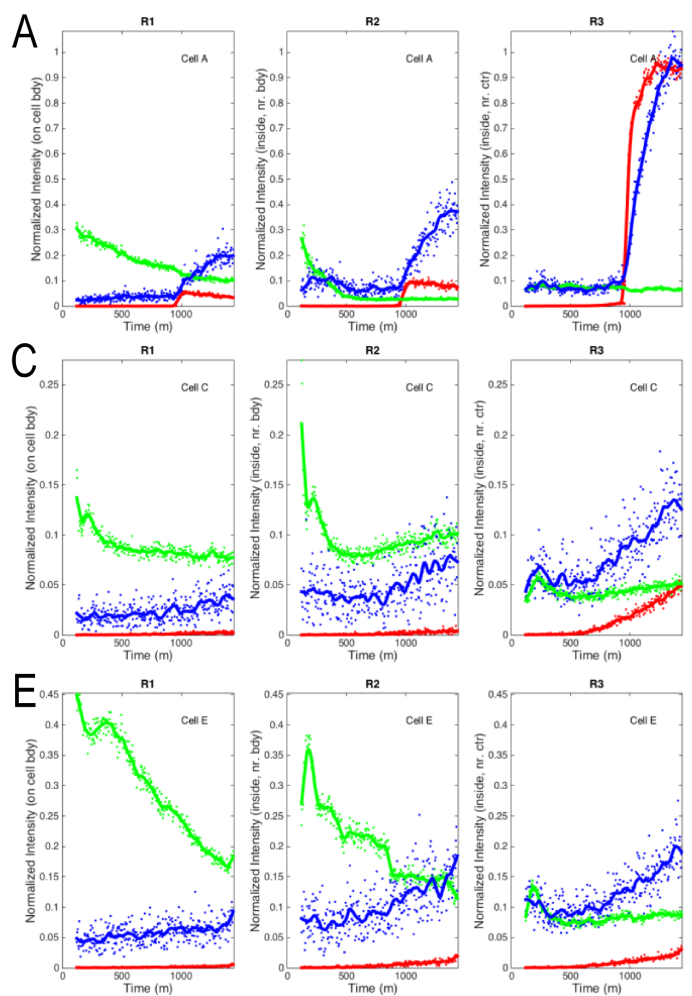

R2
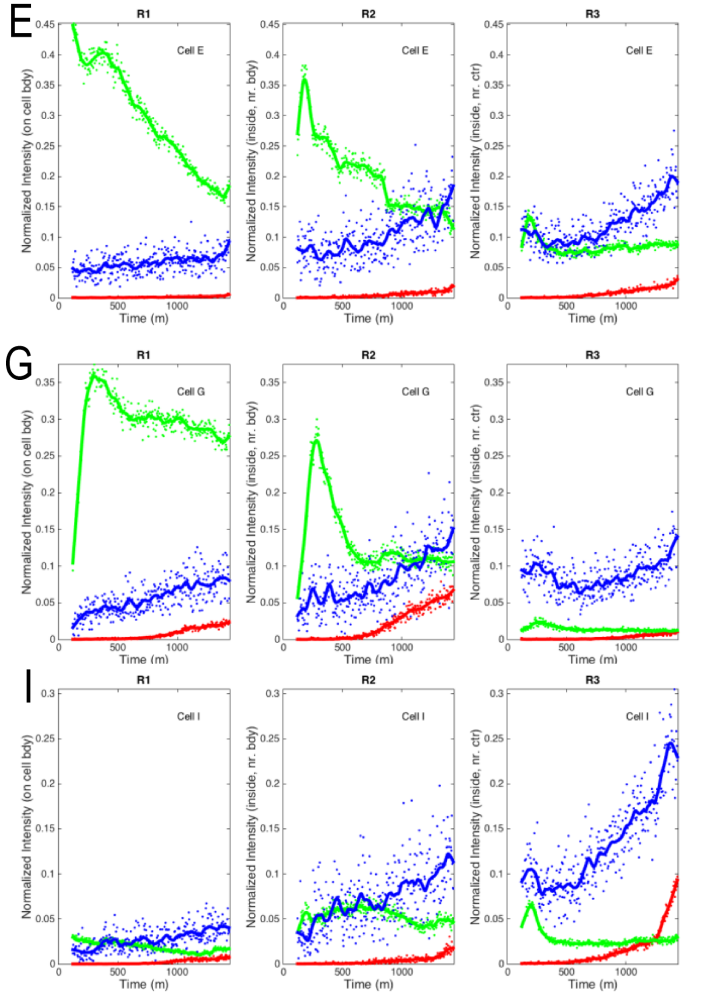
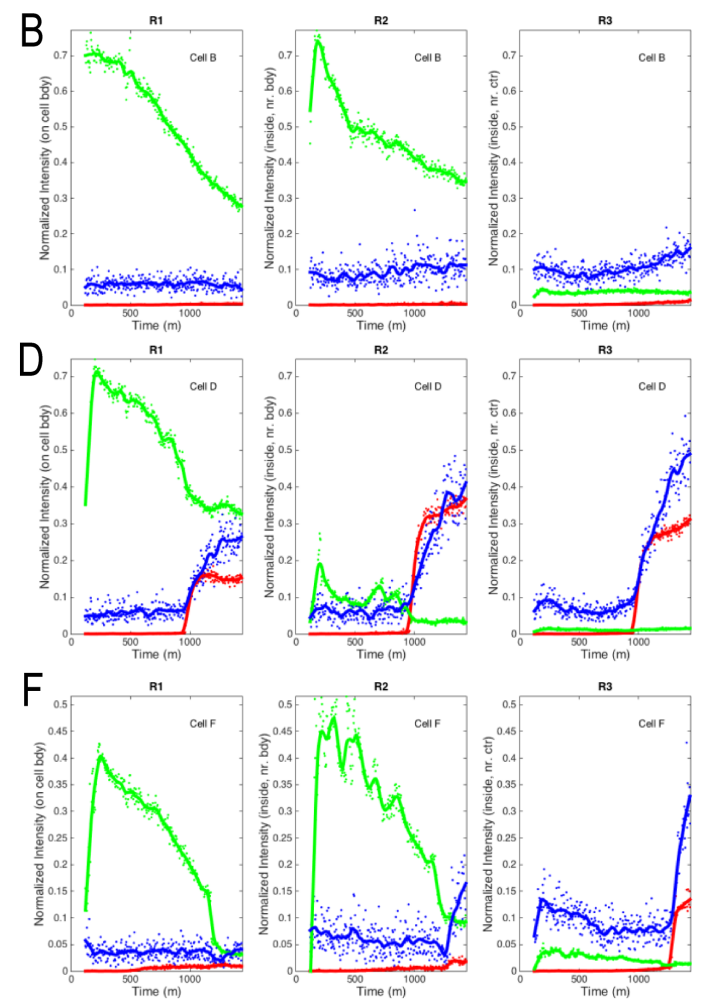

Figure 7: Analysis of the variability of the responses of the MDA-MB-231 cells to the ZnO-GFP-HCV-RGD ZnO NPs as a function of time showing the color channel signals after normalization $(\mathrm{Red}=\mathrm{PI}$, Blue $=$ Zinquin, Green $=\mathrm{ZnO}$ GFP-HCV-RGD NPs). The red, blue and green signal channels were extracted from 10 different cells (A-J) at three different locations within the cell: R1 is on the boundary of cells, R2 is $75 \%$ of the distance between the cell's center and boundary location, and R3 is within the center of a cell. The raw data are illustrated with points, and the smoothed curves for each channel are also shown (Sovitzkay-Golay smoothing). 
A

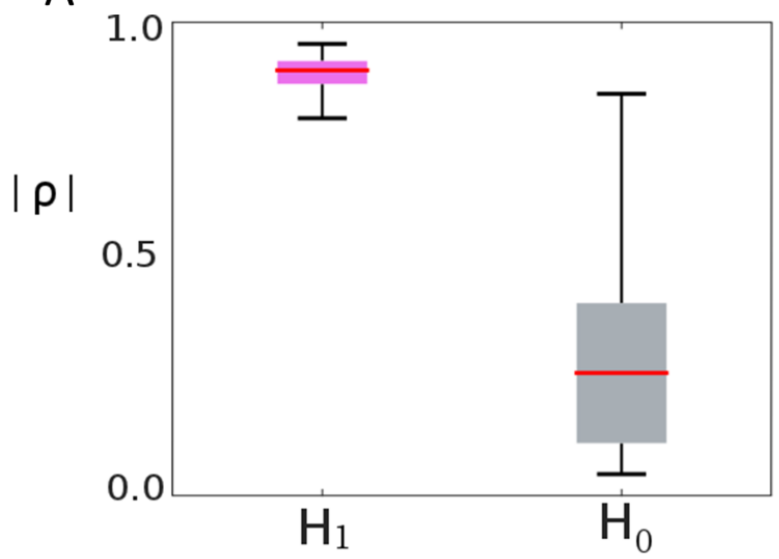

B

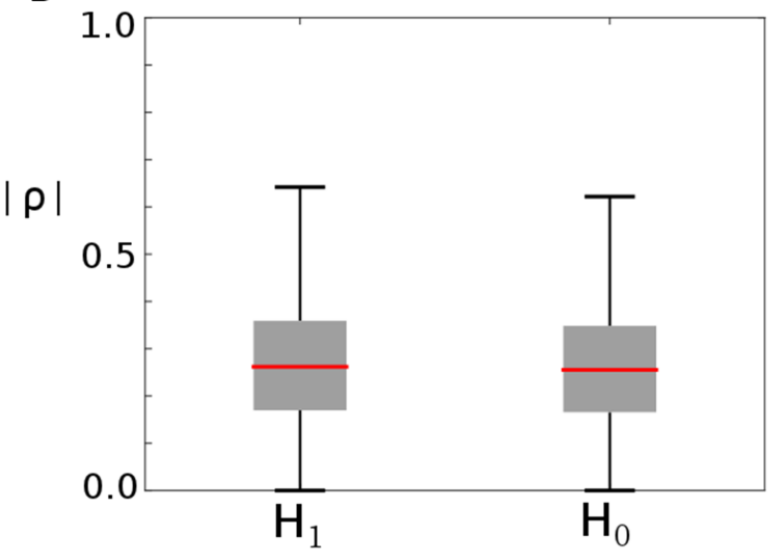

\begin{abstract}
Figure 8: Box and whisker plots [36] of the absolute values of the correlation coefficient $(|\rho|)$ between Zinquin (zincsensitive dye) levels and PI observed (A) within and (B) outside MDA-MB-231 TNBCs. Each panel shows a comparison of correlation values in sampled regions $\left(H_{1}\right)$ compared against the null hypothesis $\left(H_{0}\right)$. (A) Regions inside the cells showed highly significant correlation (KS Statistic of 0.97) between Zinquin and PI. (B) Regions outside the cells showed no discernible difference in the distributions (KS Statistic of 0.03). Red lines indicate the median values, shaded areas indicate region between $25^{\text {th }}$ and $75^{\text {th }}$ percentiles, and whiskers indicate extreme values. See Methods for details on how samples were drawn from the null hypothesis.
\end{abstract}

Bare ZnO NPs. The kinetics of intracellular release of ionic $\mathrm{Zn}^{2+}$ and cell death were further investigated for the bare $\mathrm{ZnO}$ NPs using confocal laser microscopy of live breast cancer cells. These processes were also repeated after the exposure of the cells to ionic zinc from $\mathrm{ZnCl}_{2}$. Figure 9 shows the intensity curves of the green fluorescent zinc-sensitive dye (Fluozin3) and PI (red), as well as the confocal images of MDA-MB-231 cells after exposure to the bare NPs and $\mathrm{ZnCl}_{2}$. To follow the rise of intracellular $\mathrm{Zn}^{2+}$ within a reasonable time frame, a dose as high as $150 \mu \mathrm{g} / \mathrm{ml}$ of the bare $\mathrm{ZnO}$ NPs was used [32]. In order to measure the amount of intracellular ionic zinc released and cell membrane integrity of the MDA-MB-231 exposed to the bare $\mathrm{ZnO} \mathrm{NPs}$, the fluorescent intensities of the $\mathrm{Zn}^{2+}$-sensitive dye (FluoZin3) and PI were measured for 17 cells in the imaging frame over $16 \mathrm{~h}$ exposure. The intensities of the regions of interest (ROI) selected from the cells could not be averaged as the cells showed a heterogeneous response to the particles. Representative ROI are shown in Figure 9A and B. After exposure to the bare $\mathrm{ZnO}$ NPs, the MDA-MB-231 kinetics of $\mathrm{Zn}^{2+}$ ion release and resistance to cell death between the cells in the field of view was markedly different. $41 \%$ of the MDA-MB-231 cells (7/ 17) required 1-1.5 $\mathrm{h}$ to reach the maximum concentration of ionic 


\section{WILEY-VCH}

425 zinc $\left(\mathrm{Zn}^{2+}\right)$ in the cytoplasm. In contrast, 59\% of cells $(10 / 17)$ required $3-4 \mathrm{~h}$ to reach the highest levels of intracellular $\mathrm{Zn}^{2+}$. Once the concentration of $\mathrm{Zn}^{2+}$ had reached a maximum inside the cell, some cells died immediately (Figure 9A). This correlation was monitored by increasing intracellular levels of PI and a drop in FluoZin3 dye (Figure 9A), indicating a loss of plasma membrane integrity. Figure 9B demonstrate other cells that survived for longer time at the highest levels of $\mathrm{Zn}^{2+}$ (plateau of FluoZin3).

The rise of intracellular levels of $\mathrm{Zn}^{2+}$ and its effect on the cell viability in the MDAMB-231 cells after exposure to $\mathrm{ZnCl}_{2}$ were subsequently compared to those of the bare $\mathrm{ZnO}$ NPs. $\mathrm{ZnCl}_{2}$ was used at a concentration of $250 \mu \mathrm{g} / \mathrm{ml}$. This concentration of $\mathrm{ZnCl}_{2}$ was chosen as it has the same $\mathrm{Zn}^{2+}$ concentration of $150 \mu \mathrm{g} / \mathrm{ml} \mathrm{ZnO}$ NPs used in our experiment. The same heterogeneity in the response of the MDA-MB-231 cells was observed after exposure to $\mathrm{ZnCl}_{2}$. Incubation of the cells with $\mathrm{ZnCl}_{2}$ resulted in an increase of FluoZin3 fluorescence (Figure 9C). The control elongated MDA-MB-231 cells, imaged under the same conditions, survived the laser and did not show any increase in intracellular zinc throughout the experiment, which confirms that the $\mathrm{Zn}^{2+}$ indicator did not fluoresce over time, in the absence of zinc (Figure 9D). Figure 9E-F show the green fluorescent channel of FluoZin3$\mathrm{Zn}^{2+}$ complexes and red PI fluorescent channels inside the cells after 4 and $16 \mathrm{~h}$ exposure to the bare $\mathrm{ZnO}$ NPs and $\mathrm{ZnCl}_{2}$. The MDA-MB-231 cells showed 54\% (62/115 cells) and 100\% $(115 / 115)$ death after 4 and $16 \mathrm{~h}$ incubation with the bare ZnO NPs, respectively (Figure 9E). After exposure of the MDA-MB-231 cells to $\mathrm{ZnCl}_{2}, 21 \%$ of the cells (48/230) in the frame of view were dead after $4 \mathrm{~h}$, while $90 \%$ of the cells $(207 / 230)$ were dead after $16 \mathrm{~h}$ of exposure (Figure 9F). Moreover, the distribution of $\mathrm{Zn}^{2+}$ was more diffuse inside the cytoplasm of the cells exposed to $\mathrm{ZnCl}_{2}$ (Figure $6 \mathrm{C}$ and $6 \mathrm{~F}$ ). The live imaging results for the control, $\mathrm{ZnO}$ and $\mathrm{ZnCl}_{2}$ incubations are in Supplementary information, Videos 2-4, respectively). 


\section{WILEY-VCH}

450 NPs were different: The bare $\mathrm{ZnO}$ NPs, showed a clear time dependent increase in 451 intracellular dissolution, while the RGD-targeted $\mathrm{ZnO}$ NPs showed low intracellular 452 dissolution initially and then a sudden burst of ionic zinc.

453

454

455

456 


\section{WILEY-VCH}

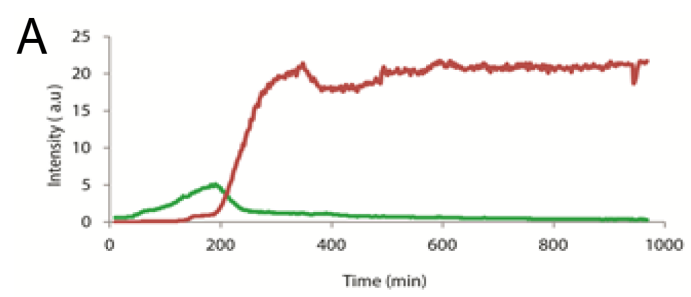

B

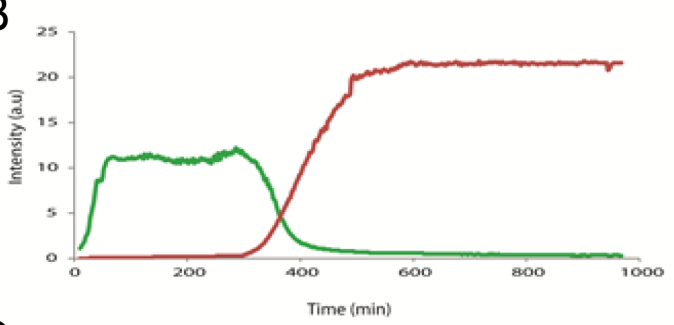

$\mathrm{C}$
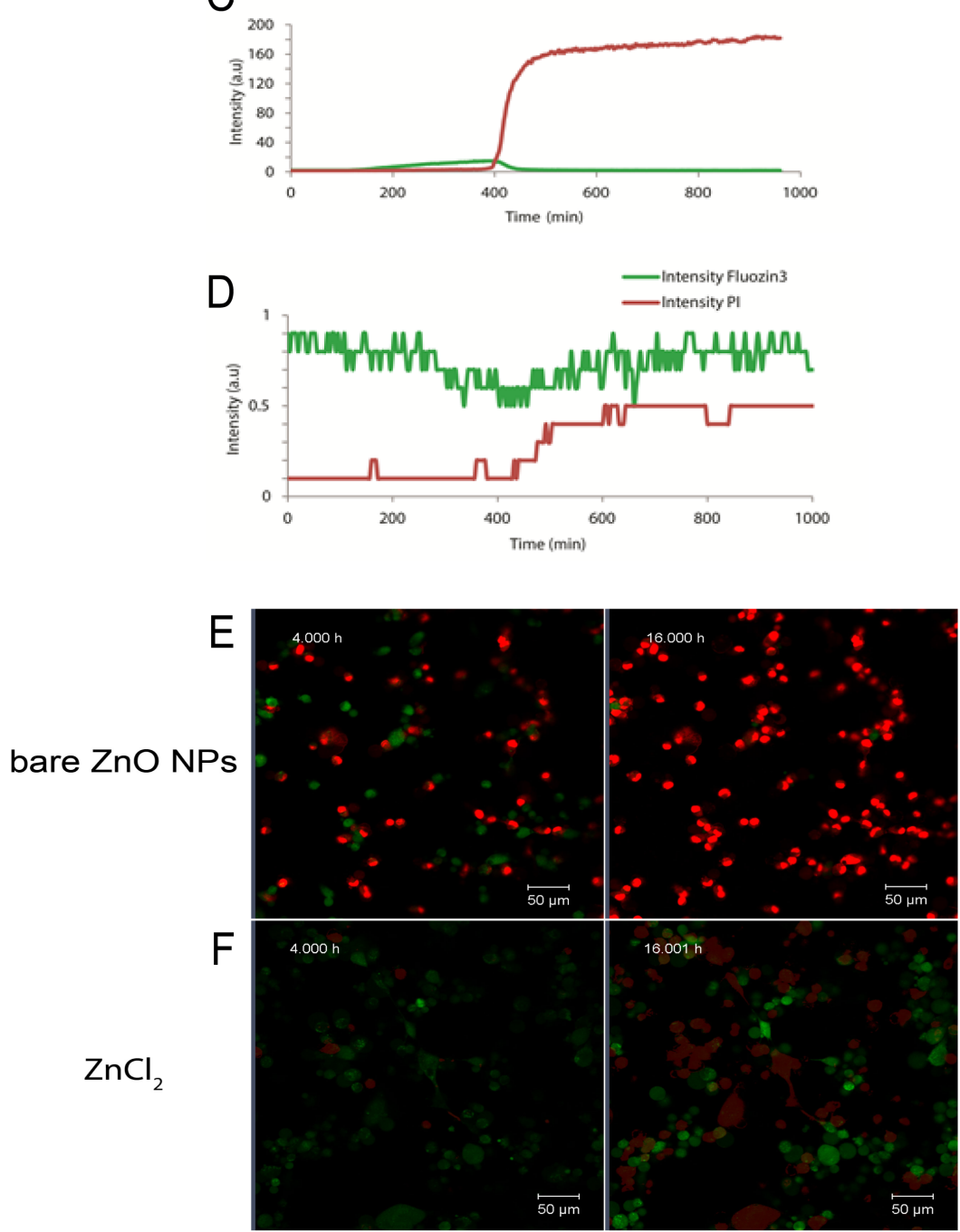

Figure 9: (A-D) Cytoplasmic $\mathrm{Zn}^{2+}$ and PI concentration of MDA-MB-231 cells after exposure to the bare ZnO NPs and $\mathrm{ZnCl}_{2}$ showing an increase in intracellular $\mathrm{Zn}^{2+}$ and subsequent cell death. The MDA-MB-231 cells were loaded with the cell-permanent $\mathrm{Zn}^{2+}$ indicator FluoZin3-AM prior to incubation with (A) $150 \mu \mathrm{g} / \mathrm{ml}$ bare ZnO NPs, (B) $250 \mu \mathrm{g} / \mathrm{ml}$ $\mathrm{ZnCl}_{2}$, or (D) imaging buffer (NA control). (E and $\mathbf{F}$ ) Confocal images of MDA-MB-231 cells show the intracellular green fluorescent FluoZin3- $\mathrm{Zn}^{2+}$ and red PI and illustrate the heterogeneity of the cellular responses to $\mathrm{ZnO}$ and $\mathrm{ZnCl}_{2}$, respectively. The MDA-MB-231 cells were loaded with the cell-permeant $\mathrm{Zn}^{2+}$ indicator FluoZin3-AM prior to incubation with $150 \mu \mathrm{g} / \mathrm{ml}$ of bare $\mathrm{ZnO}$ NPs or equivalent zinc ions concentration from $\mathrm{ZnCl}_{2}$. FluoZin3 fluoresces green upon binding ionic zinc. Toxic levels of $\mathrm{Zn}^{2+}$ ions inside the cell resulted in loss of cell membrane integrity and cellular penetration of PI 


\section{WILEY-VCH}

\section{Discussion}

TNBCs represent an important clinical challenge because these cancers do not respond to endocrine therapy or other available targeted agents [37, 38]. Therefore, agents that specifically target and kill these cells are of great importance. Compared with other NMs, ZnO-based NPs are attractive due to their selective killing of cancer cells $[18,39]$. The data from the current study showed that although both bare and targeted ZnO NPs were toxic to both the MDA-MB-231 TNBCs and MCF-7 (ER ${ }^{+}$) breast cancer cells, RGD targeting enhanced uptake and induction of cell death of TNBCs. These findings support previous work showing that the release of $\mathrm{Zn}^{2+}$ ions, following incubation of $\mathrm{ZnO}$ NPs with MCF-7 breast cancer epithelial cells, triggers the generation of reactive oxygen species, resulting in damage to the plasma membrane [16]. The results also demonstrate, for the first time, that ZnO-GFP-HCV-RGD NPs are internalized by TNBCs and show toxicity at lower doses compared to the bare $\mathrm{ZnO}$ NPs after $24 \mathrm{~h}$ exposure. The higher toxicity of the RGD-targeted $\mathrm{ZnO}$ NPs, could be due to a higher amount of internalization (and hence $\mathrm{Zn}^{2+}$ ion release) of the targeted $\mathrm{ZnO}$ NPs through the integrin $\alpha \mathrm{v} \beta 3$ receptors expressed by the MDA-MB-231 TNBCs compared to the bare ZnO NPs. This finding of the ability of the RGD-targeted ZnO NPs to effectively kill TNBCs, which account for a high proportion of breast cancer mortality due to the lack of effective therapies [64], will open new options for this material in cancer therapy.

Only few reports on the cellular uptake of $\mathrm{ZnO} \mathrm{NMs}$ are available [19, 23, 40-42]. Confocal microscopy has shown that $\mathrm{ZnO}$ NP remnants are internalised by caveolae mediated uptake in BEAS-2B cells and toxic $\mathrm{Zn}^{2+}$ has been shown to accumulate in the lysosomal compartment in RAW 264.7 cells [23]. ZnO NPs are rapidly internalized by HELA cells, and dissolve in the lysosomal compartments [43]. Lin et al. showed agglomerates of ZnO NPs in endosomes in bronchoalveolar carcinoma- derived cells (A549) after $24 \mathrm{~h}$ exposure to 12 


\section{WILEY-VCH}

$\mu \mathrm{g} / \mathrm{ml} \mathrm{ZnO} \mathrm{NPs} \mathrm{[44],} \mathrm{however,} \mathrm{their} \mathrm{study} \mathrm{lacks} \mathrm{EDX} \mathrm{data} \mathrm{to} \mathrm{confirm} \mathrm{the} \mathrm{presence} \mathrm{of} \mathrm{ZnO}$ NPs. There is still much debate around whether the $\mathrm{ZnO}$ NMs are taken up by cancer cells and then dissolve only intracellularly or whether they dissolve in the extracellular matrix releasing ionic zinc which diffuses into the cells. One study successfully directed fluorescent $\mathrm{ZnO} \mathrm{NWs}$ to tumours in vivo by targeting the integrin $\alpha \mathrm{v} \beta 3$ receptors [11] but reference to whether the wires were internalised by the cells or to where the zinc dissolved and exerted its toxic effects was not highlighted. Here, we show for the first time (using a $\mathrm{Zn}^{2+}$-sensitive dye) that in most cells, a rise of intracellular $\mathrm{Zn}^{2+}$ precedes cell death in the MDA-MB-123 TNBCs after exposure to ZnO NPs. Dissolution studies of the bare ZnO NPs in the absence of cells, in the HEPES confocal imaging buffer at $\mathrm{pH} 7.4$, showed that the release of ionic zinc $\left(\mathrm{Zn} 2^{+}\right)$was $<9 \mu \mathrm{g} / \mathrm{ml} \mathrm{Zn}{ }^{2+}$. Therefore, any rise in intracellular $\mathrm{Zn}^{2+}$ upon exposure to the bare $\mathrm{ZnO}$ NPs is likely due to the acidic dissolution of the ZnO NPs inside the intracellular vesicles and the local release of toxic $\mathrm{Zn}^{2+}$ ions.

The breast cancer cells showed inter- and intra- cellular heterogeneity in response to the ZnO NPs. A marked variability between the cell responses of the MDA-MB-231 cells to the ZnO-GFP-HCV-RGD NPs was measured. This variability may be due to several factors, such as the number of ZnO-GFP-HCV-RGD NPs internalised by each cell and the route by which they are internalised. Another key factor involves the potential variability of each cell within the population to $\mathrm{Zn}^{2+}$, which could be due to differences in cell function such as metabolism and/or the phenotype of the individual cells. This heterogeneity of cancer cells introduces significant challenges in designing effective treatment strategies. Inter-tumour heterogenetic impacts significantly on stratifying patients, the selection of therapies and development of targeted therapeutics. Intra-tumour heterogeneity has implications in the emergence of resistance to treatment, identification of driver events, defining the phenotype of recurrent disease and can impact the effectiveness of treatments when using drugs in combination [33]. 


\section{WILEY-VCH}

517 Therefore, understanding and characterizing heterogeneity is crucial in the development of refined treatment strategies. The ability of ZnO NPs to kill the TNBCs that could be resistant to classic treatments while possessing potent tumor-forming capacity is another advantage of using this material in cancer therapeutics. The observed heterogeneity in the response of the breast cancer cells to the $\mathrm{ZnO}$ NPs could be explained since most cancers comprise a heterogeneous population of cells with different proliferative and tumorigenic potentials [45, 46]. According to the recent cancer stem cell hypothesis, a tumor consists of differentiated highly proliferative cells, and undifferentiated low-cycling cells with self-renewal capacity, the so called cancer stem cells (CSCs) [47]. CSCs should have a higher resistance than the differentiated cancer cells to radiation and chemotherapy [48]. The presence and the percentage of these CSCs expressed by the MCF-7 and the MDA-MB-231 cells were measured. Among the markers that are currently used to identify breast CSCs [49], the expression of CD44, CD24, CD90, and EpCAM (epithelial cell adhesion molecule) were tested. CSCs are reported as $\mathrm{CD} 44^{+}, \mathrm{CD} 24^{-}, \mathrm{EpCAM}^{-/ \text {low }}$ and $\mathrm{CD}^{-} 0^{-}[50]$. In this study, the MDA-MB-231 and the MCF-7 cells showed different expression of these markers (Supplementary information, Figure S8); while the MCF-7 were CD $44^{\text {low }} / \mathrm{CD} 24^{+} / \mathrm{EpCAM}^{\text {high }}$ and $\mathrm{CD}^{+}$(Supplementary information, Figure S8A), the MDA-MB-231 cells were

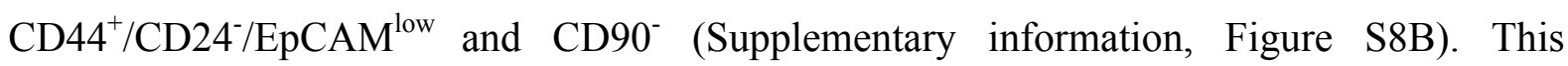
coincides with the published work for these cells $[50,51] . \mathrm{CD}^{+} 4^{+} / \mathrm{CD} 24^{-}$breast cancer cells were reported to disseminate in the bone marrow and they were also resistant to chemotherapy [52]. Therefore, the ability of ZnO NPs to eradicate these CSCs could further support the therapeutic value of this material for the treatment of cancer.

The kinetics of intracellular dissolution of the bare ZnO NPs and RGD-targeted ZnO NPs were different: The bare ZnO NPs, showed a clear time dependent increase in intracellular dissolution, while the RGD-targeted ZnO NPs showed low intracellular dissolution initially 


\section{WILEY-VCH}

and then a sudden burst of ionic zinc, indicating that $\mathrm{ZnO} \mathrm{NP}$ toxicity in both cell types is due to a $\mathrm{pH}$-triggered, intracellular release of ionic $\mathrm{Zn}^{2+}$. This finding is most likely due to the different mechanisms of internalisation of the bare and the RGD-targeted NPs and therefore altered intracellular distribution [53]. It has been reported that the RGD-grafted NPs enter cells through integrin or clathrin-mediated endocytosis and are localised in perinuclear regions while the bare $\mathrm{ZnO}$ NPs are hypothesized to be taken up by the cells by clathrinindependent endocytosis, and then end up in the acidic lysosomes of the cells where they dissolve to release the zinc ions and labile zinc complexes [19, 23, 24, 54].

In conclusion, a nanoparticle platform was developed which is capable of delivering a high local dose of $\mathrm{Zn}^{2+}$ ions from $\mathrm{ZnO} \mathrm{NMs}$ intracellularly, coupled to simultaneous targeteddelivery to destroy TNBCs. It is expected that this approach could be adapted to attach other ligands for the future development of cell-targeted ionic nanoparticle therapeutics to treat TNBCs. This is clinically promising since it has been reported that zinc may protect normal human lymphocytes against DNA-damaging action and increase this action in human myelogenous leukaemia K562 cancer cells [17], which indicates the dual action of this element in dependency of target cells and can be useful in cancer therapy. More generally, these observations highlight the need for dynamic and static characterization of NMs-cell interactions at the cellular level in order to understand how cellular uptake and dissolution of $\mathrm{ZnO}$ NMs can be correlated to the kinetics of cell death. Improving our understanding of how targeted $\mathrm{ZnO}$ NMs interact with cells at the cellular level using both dynamic and quantitative imaging techniques is paramount for appreciating the heterogeneity and dynamics of their interactions with cancer cells and for extracting statistically relevant information at the cellular level about these interactions. An improved understanding and quantitative characterization of the heterogeneity of cancer cell response to nanomaterial therapeutics will be crucial in the development of refined treatment strategies. 


\section{WILEY-VCH}

\section{Materials and Methods}

Bare ZnO NPs were purchased from SkySpring Nanomaterials, Inc., (product number 8410DL, Westhollow Drive, Houston, USA) at 99.8\% purity. The powder was white to light yellow in colour, and was stored at room temperature (RT) and vacuum sealed.

Functionalization of the ZnO nanoparticles. Cell targeting of the ZnO NPs was achieved using an immobilization of an engineered protein which is composed of a cell targeting peptide domain, a $\mathrm{ZnO}$ binding peptide domain and a green fluorescence protein (GFP) for tracking the modified $\mathrm{ZnO}$ NPs by fluorescence microscopy. The cell targeting domain comprises peptides with established cell-specific tumor targeting sequences (CDCRGDCFC) [55]. The $\mathrm{ZnO}$ binding motif is a hexapeptide (HCVAHR) discovered using a computationally assisted peptide design approach [56]. These two peptide domains were connected via a glycine linker (GGGTRGGG) to ensure flexibility. The thrombin recognition sequence (LVPRGS) was designed to be located between GFP and the zinc oxide binding peptide to facilitate GFP cleavage from the HCV-RGD domain, if required (The protein is abbreviated hereafter as GFP-HCV-RGD).

In order to engineer the fusion protein, synthetic DNA corresponding to HCV-RGD domains with linker amino acids, and having restriction enzyme recognition sites (NcoI and BamHI) was purchased from GenScript (Piscataway, NJ, UAS). This nucleotide sequence was cloned into the C-terminus of the GFP gene in the pET-3a vector using NocI and BamHI restriction sites. The nucleotide sequence purchased from GenScript and the amino acid sequence of the obtained GFP-HCV-RGD fusion protein is shown in Supplementary Figure S1A and S1B, respectively. As a negative control for a cell-targeting assay, the RGD sequence in the plasmid was changed to GGG using the established Agilent QuickChange protocol. 


\section{WILEY-VCH}

The plasmids were then transformed and expressed in E. coli strain BL21 (DE3). After culturing in $\mathrm{LB}$ medium at $37{ }^{\circ} \mathrm{C}$ with $100 \mathrm{mg} / \mathrm{L}$ ampicillin for $16 \mathrm{~h}$, the cells were pelleted from the media and resuspended in $50 \mathrm{mM}$ HEPES, $100 \mathrm{mM} \mathrm{NaCl}, \mathrm{pH} 7.5$ with a protease inhibitor (complete Mini EDTA-free, Roche) and lysed using a DNase, RNase and Lysozyme cocktail at r.t. for 30 minutes; followed by sonication. Cell debris was removed via centrifugation, and supernatants were heat treated at $60^{\circ} \mathrm{C}$ for $10 \mathrm{~min}$. The heated solution was re-centrifuged and the supernatant was dialyzed against $50 \mathrm{mM}$ HEPES, $100 \mathrm{mM} \mathrm{NaCl}, \mathrm{pH}$ 7.5 at $4{ }^{\circ} \mathrm{C}$ for overnight. The resulting supernatant was purified by size exclusion chromatography (SEC) utilizing a Superose 6 column (GE Healthcare Life Sciences). The protein elution was monitored by a UV-Vis detector at dual wavelengths of $280 \mathrm{~nm}$ (protein) and $490 \mathrm{~nm}(\mathrm{GFP})$.

After preparing the engineered protein, it was diluted with the HEPES buffer (50 mM HEPES, $100 \mathrm{mM} \mathrm{NaCl}, \mathrm{pH} 7.5$ ) to an absorbance of 1.6 at $490 \mathrm{~nm}$. The bare $\mathrm{ZnO}$ NPs were suspended in the same buffer at a concentration of $10 \mathrm{mg} / \mathrm{ml}$. The $\mathrm{ZnO}$ NPs suspension was diluted with the protein solution at a ratio of $1: 9 \mathrm{vol} / \mathrm{vol}$ (i.e. concentration of the $\mathrm{ZnO}$ NPs is $1 \mathrm{mg} / \mathrm{ml}$ ) and then incubated overnight at room temperature (RT) in the dark with gentle shaking. Finally, the NPs dispersions were centrifuged at $13,000 \mathrm{rpm}$ for five min on a tabletop centrifuge. To test the efficiency of binding of the targeting peptide (GFP-HCV-RGD) and the control peptide (GFP-HCV-GGG) to ZnO NPs, the absorbance of the protein solution, before and after incubation with the particles, was measured at $490 \mathrm{~nm}$ (Supplementary information, Figure S2A and S2B, respectively).

Size and morphology of the zinc oxide nanoparticles. The morphology of bare and targeted ZnO NPs was evaluated on a JEOL 2100F transmission electron microscope operated at 200 $\mathrm{kV}$. A $3 \mu \mathrm{l}$ droplet of NPs in MEM (10\% FBS) solution was applied onto a 300 mesh holeycarbon $\mathrm{Cu}$ grids (TAAB). Excess solution was blotted with filter paper and the grid was 


\section{WILEY-VCH}

616 plunged into liquid ethane using a Leica EM GP plunge freezer. The grid was then transferred

617

618

619

620

621

622

623

624

625

626

627

628

629

630

631

632

633

634

635

636

637

638

639

640

under liquid nitrogen into the microscope using a Gatan 914 high tilt liquid nitrogen cryo transfer holder. Images were recorded at a magnification of $20000 \mathrm{X}$, with a defocus of -1 to $-2 \mu \mathrm{m}$, and under low dose conditions (a dose of 5 electrons per $\AA^{2}$ per second) with a Gatan Orius SC1000 camera. The hydrodynamic size of NPs in MEM cell culture medium $(10 \%$ FBS) was characterized by dynamic light scattering using a Zetasizer Nano ZSP (Malvern Instruments).

Cell Culture. Breast cancer cell lines (MCF-7 and MDA-MB231) were purchased from ATCC (Manassas, VA, USA). The MDA-MB-231 and MCF-7 were maintained in DMEM and MEM, respectively. DMEM and MEM media were supplemented with $10 \%$ fetal bovine serum (FBS) and Penicillin/Streptomycin solution (100 units/ml penicillin, $100 \mu \mathrm{g} / \mathrm{ml}$ streptomycin). Cells were maintained in a humidified incubator at $37^{\circ} \mathrm{C}$ and $5 \% \mathrm{CO}_{2}$. In all viability assays, cells were used from passages 5-25 and plated in flat-bottomed 96-well plates (Fisher Scientific Ltd, UK). The MCF-7 cells were plated at a density of $3 \times 10^{5}$ cells $\mathrm{mL}^{-1}\left(9 \times 10^{4}\right.$ cells $\left./ \mathrm{cm}^{2}\right)$, while MDA-MB-231 were plated at a density of $2 \times 10^{5}$ cells $\mathrm{mL}^{-1}$ $\left(6 \times 10^{4}\right.$ cells $\left./ \mathrm{cm}^{2}\right)$. The plates were incubated at $37^{\circ} \mathrm{C}$ and $5 \% \mathrm{CO}_{2}$ in a humidified incubator for 24 hours. Then, supernatants from the culture plates were removed and fresh aliquots of growth medium containing different concentrations of ZnO NPs (bare and targeted) were added to the cells and then incubated with the cells for toxicity and $\mathrm{IC}_{50}$ analysis.

Alamar blue assay. Alamar Blue detects the impairment of cellular metabolism [57]. The MDA-MB-231 and MCF-7 cells were exposed to targeted (10, 20, 25, 30, 40, and $50 \mu \mathrm{g} / \mathrm{ml})$ and bare $(10,20,25,30,35,40,50$, and $60 \mu \mathrm{g} / \mathrm{ml}) \mathrm{ZnO} \mathrm{NPs}$, as well as ionic $\mathrm{Zn}^{2+}$ from $\mathrm{ZnCl}_{2}$ (equivalent to zinc ions released from $0,10,20,25,30$ and $50 \mu \mathrm{g} / \mathrm{ml}$ of $\mathrm{ZnO}$ ) for $24 \mathrm{~h}$. The Alamar blue assay was used according to the manufacturer's protocol. The spectrophotometric absorbance was measured at two wavelengths; $570 \mathrm{~nm}$ (reduced form of 


\section{WILEY-VCH}

641 Alamar Blue) and $600 \mathrm{~nm}$ (oxidized form of Alamar Blue) using a Bio-Rad plate-reader. The

642

643

644

645

646

647

648

649

650

651

652

653

654

655

656

657

658

659

660

661

662

mean absorbance reading from the wells without the particles was used as the control $(100 \%$ viability). The toxicity of the targeting peptide (GFP-HCV-RGD) to the cells was tested at the highest concentration used in the assays $(60 \mu \mathrm{g} / \mathrm{ml})$. In this assay, the cells were registered as viable, as long as they maintained their ability to reduce Alamar Blue. All experiments were carried out in triplicate. The $\mathrm{IC}_{50}$ was generated from the dose-response curves for both cell lines.

Lactate dehydrogenase (LDH) assay. LDH is a cytoplasmic enzyme that is released into the supernatant upon cell lysis and measures membrane integrity [58]. The LDH released upon exposure to $\mathrm{ZnO}$ NPs from damaged cells into the culture media was determined by a Takara LDH Kit (Takara, CA, USA). The breast cancer cell lines were exposed to bare ZnO NPs (10, $20,25,30,35,40,50$, and $60 \mu \mathrm{g} / \mathrm{ml}$ ) for 24 and $48 \mathrm{~h}$. The assay was used according to the manufacturer's protocol. The LDH assay requires a low-serum medium because FBS contains LDH and can thus increase background absorbance [59]; therefore all culture media used were supplemented with $1 \%$ FBS. The mean absorbance reading from the wells without the particles was used as the negative control (100\% viability), and those treated with $1 \%$ Triton X-100 was used as a positive control (0\% viability) [16]. Absorbance was measured using a Bio-Rad plate-reader at $490 \mathrm{~nm}$.

As the $\mathrm{ZnO}$ NPs could interact with dyes in the colorimetric assays, control experiments using the Alamar Blue and LDH assays were performed using the same protocol as the experiments in this study, but without the cells-in order to confirm that the ZnO NPs did not interfere with the viability assays. No effects were observed for any of the assays.

ZnO nanoparticles binding assay. For all binding studies, cells were first cultured for 24 hours at $10^{5}$ cells $/ \mathrm{cm}^{2}$. The cells were then washed twice and blocked for one hour in blocking buffer (1\% BSA in HBSS) prior to treatment to inhibit cellular uptake. Cells were 


\section{WILEY-VCH}

then treated for 30 minutes with $150 \mu \mathrm{g} / \mathrm{ml} \mathrm{ZnO}-\mathrm{GFP}-\mathrm{HCV}$-RGD NPs in binding buffer (2 $\mathrm{mM} \mathrm{CaCl}_{2}, 1 \% \mathrm{BSA}$ in HBSS) at $4^{\circ} \mathrm{C}$. ZnO-GFP-HCV-RGD- treated cells were compared to either untreated or ZnO-GFP-HCV-GGG NPs as negative controls. Prior to analysis, cells were washed three times in binding buffer at $4^{\circ} \mathrm{C}$.

For laser scanning confocal microscopy, cells were cultured on an 8-chamber cover glass slide (Nunc, NY, USA; $0.19 \mathrm{~mm}$ thick, $0.8 \mathrm{~cm}^{2} /$ well) using the Zeiss LSM 710 . A 488 $\mathrm{nm}$ laser line was used for excitation and images were analyzed using ImageJ software. Total cell integrated density was calculated from representative confocal images of ZnO-GFPHCV-GGG and ZnO-GFP-HCV-RGD conditions. Total cell integrated density was corrected to the background signal to give a corrected total cell fluorescence (CTCF) that was normalized to cell area (CA) by dividing CTCF by CA, to preclude the cell size bias. 50 and 30 cells from ZnO-GFP-HCV-GGG and ZnO-GFP-HCV-RGD conditions were analyzed respectively. To investigate the distribution of fluorescence intensity, representative confocal images were divided into 100 tiles and integrated density was calculated.

For the fluorimetric based binding study, cells were cultured in 96-well black tissue culture plate. After treatment, fluorescence intensity was measured using GloMax-Multi detection system plate reader (Promega, WI, USA), using $\lambda$ exc of $490 \mathrm{~nm}$ and $\lambda$ em $510-570$ nm filter. Fluorescence signal from untreated cells was used as a blank.

To determine the binding of ZnO-NP using FACS, cells were cultured in 6-well tissue culture plate. Cells were excited using a $488 \mathrm{~nm}$ laser and emission was measured through FL1 channel (530/30). At least 104 cells were quantified on a FACSCanto II flow cytometer (BD bioscience, Franklin lakes, NJ) equipped with FlowJo 7.6 software.

Cell imaging by transmission electron microscopy: Cells were seeded on 6-well plates at a density of $300 \mathrm{k}$ cells per well and exposed to NPs at a concentration of $30 \mu \mathrm{g} / \mathrm{mL}$ for $3 \mathrm{~h}$. Following incubation, cells were rinsed briefly in saline $(0.9 \% \mathrm{NaCl})$ to remove any non- 


\section{WILEY-VCH}

ingested particles and were then fixed in $2 \%$ gluteraldehyde (Sigma) and $2 \%$ formaldehyde (Sigma) in $0.1 \mathrm{M}$ sodium cacodylate (Sigma) buffer at $\mathrm{pH} 7.4$ for $1 \mathrm{~h}$ at room temperature. The fixatives were then removed by washing cells with $0.1 \mathrm{M}$ sodium cacodylate buffer 3 times. Cells were scraped and transferred into $1.5 \mathrm{~mL}$ Eppendorf tubes and cell pellets were obtained by centrifugation at $10,000 \mathrm{~g}$ for 20 min. Samples were embedded without bulk staining with osmium tetroxide. They were dehydrated in a graded ethanol series of $50 \%$, $70 \%, 95 \%$, and $100 \%$ (volume ratio of ethanol to $\mathrm{DI}-\mathrm{H}_{2} \mathrm{O}$ ) ethanol for $5 \mathrm{~min}$ each then rinsed three times in dry acetonitrile (Sigma) for an additional $10 \mathrm{~min}$ each, all at RT. After dehydration, samples were progressively infiltrated with an Epon based resin, created by combining 23.5 g Epoxy embedding medium (Sigma), $12.5 \mathrm{~g}$ dodecenyl succinic anhydride (Agar scientific), $14 \mathrm{~g}$ methyl acid anhydride (Agar scientific), $0.75 \mathrm{~mL}$ benzyl dimethylamine (Agar scientific). Samples were first re-suspended in 25\% resin/acetonitrile solution (volume ratio of resin to acetonitrile) and centrifuged for $30 \mathrm{~s}$ at 2,000 g. This step was repeated with $50,75,100,100$ and $100 \%$ resin. Samples were cured at $100{ }^{\circ} \mathrm{C}$ for $2 \mathrm{~h}$ [60]. Thin sections $(70 \mathrm{~nm})$ were cut directly into a water bath using an ultramicrotome with a diamond knife with a wedge angle of 35 degrees. Sections were immediately collected on bare, 250 mesh gold TEM grids (Agar Scientific), dried and kept under vacuum for TEM analysis. HRTEM and HAADF-STEM/EDX analyses were performed on an FEI Titan 80300 scanning/transmission electron microscope (S/TEM) operated at $80 \mathrm{kV}$, fitted with a Cs (image) corrector and a SiLi EDX spectrometer (EDAX, Leicester UK). STEM experiments were performed with a convergence semi-angle of $14 \mathrm{mrad}$ and inner and outer HAADF collection angles of 49 and $239 \mathrm{mrad}$, respectively. The probe diameter was $<0.5 \mathrm{~nm}$.

Confocal Laser Scanning Microscopy. For live imaging, the MDA-MB-231 cells were cultured for $48 \mathrm{~h}$ on $35 \mathrm{~mm}$ glass-based culture dishes (Nest Biotech Co, LTD, 35X12 mm style, $20 \mathrm{~mm}$ glass bottom) at $6 \times 10^{4}$ cells $/ \mathrm{cm}^{2}$. The cells were rinsed once with the HEPES 


\section{WILEY-VCH}

confocal imaging buffer at $\mathrm{pH} 7.4$ and $37^{\circ} \mathrm{C}$. The cells were then loaded with $5 \mu \mathrm{M}$ of the cell-permeant $\mathrm{Zn}^{2+}$ indicator FluoZin3-AM (Invitrogen, UK) in $1 \mathrm{ml}$ of the HEPES confocal imaging buffer for $20 \mathrm{~min}$ at $37^{\circ} \mathrm{C}$ for the bare $\mathrm{ZnO} \mathrm{NPs}$ and $\mathrm{ZnCl}_{2}$, or with $10 \mu \mathrm{M}$ or of the cell-permeant $\mathrm{Zn}^{2+}$ indicator Zinquin-AM in $1 \mathrm{ml}$ of the HEPES confocal imaging buffer for 30 min at $37^{\circ} \mathrm{C}$ for the $\mathrm{ZnO}-\mathrm{GFP}-\mathrm{HCV}-\mathrm{RGD}$ NPs. After rinsing the cells twice with imaging buffer at $37^{\circ} \mathrm{C}$ to remove any dye that is non-specifically associated with the cell surface, the cells were incubated for a further $30 \mathrm{~min}$ to allow complete de-esterification of intracellular AM esters of Zinquin or FluoZin3. PI $(20 \mu \mathrm{g} / \mathrm{ml})$ was prepared in $1 \mathrm{ml}$ HEPES confocal imaging buffer and added to the cells (the final concentration incubated with the cells was 10 $\mu \mathrm{g} / \mathrm{ml}$ ). Then the bare or the targeted $\mathrm{ZnO}$ NPs were prepared in $1 \mathrm{ml}$ HEPES imaging buffer and were added to the cells just before imaging (final concentration exposed to the cells is $150 \mu \mathrm{g} / \mathrm{ml}$ ). $\mathrm{ZnCl}_{2}$ was used at a concentration of $250 \mu \mathrm{g} / \mathrm{ml}$. This concentration of $\mathrm{ZnCl}_{2}$ was chosen as it has the same $\mathrm{Zn}^{2+}$ concentration as $150 \mu \mathrm{g} / \mathrm{ml} \mathrm{ZnO}$. Confocal live imaging was started immediately after addition of the $\mathrm{ZnO} \mathrm{NPs}$ and $\mathrm{ZnCl}_{2}$ to the cells using a Zeiss LSM 710 confocal microscope with the environmental chamber set to $37^{\circ} \mathrm{C}$. Control MDA-MB231 cells were incubated with $1 \mathrm{ml}$ of the HEPES confocal imaging buffer alone. For the bare $\mathrm{ZnO}$ NPs and $\mathrm{ZnCl}_{2}$, the $488 \mathrm{~nm}$ laser line was used to excite FluoZin3 ( $\lambda$ exc $\backslash \lambda \mathrm{em}=494 / 516$ $\mathrm{nm})$ and the $561 \mathrm{~nm}$ laser was used to excite PI $(\lambda \operatorname{exc} \backslash \lambda \mathrm{em}=538 / 617 \mathrm{~nm})$. Images were acquired over a time period of $16 \mathrm{~h}$ ( $1 \mathrm{frame} / 2 \mathrm{~min}$ ). For the $\mathrm{ZnO}-\mathrm{GFP}-\mathrm{HCV}-\mathrm{RGD}$, the 405 nm laser line was used to excite Zinquin $(\lambda \operatorname{exc} \backslash \lambda \mathrm{em}=344 / 385 \mathrm{~nm})$, the $561 \mathrm{~nm}$ laser was used to excite PI ( $\lambda$ exc $\backslash \lambda \mathrm{em}=538 / 617 \mathrm{~nm})$ and the $488 \mathrm{~nm}$ laser was used to excite GFP labelled $\mathrm{ZnO}-\mathrm{HCV}-\mathrm{RGD}(\lambda$ exc $\backslash \lambda \mathrm{em}=488 / 509 \mathrm{~nm})$. Since the dissolution of the targeted $\mathrm{ZnO}$ NPs was slow, images were acquired over a time period of $24 \mathrm{~h}$ and at lower frequency (1 frame/4 min) to reduce the damaging effect of the laser. A $20 \mathrm{x}$ objective/0.8 NA was used 


\section{WILEY-VCH}

and the pinhole was set at $1 \mathrm{AU}$. Images and fluorescence quantification were carried out using ZEN 2009 Confocal Software.

Confocal imaging processing: One z-plane location was extracted from the stack, and the full image sequence from that depth slice was stored in LSM format. Data were loaded into Matlab Version 2014b (The Mathworks, Inc) as unsigned 8-bit data. The data were found to be interleaved, with odd and even-numbered frames. The odd-numbered frames contained the data of interest (color channels). The odd-numbered frames were extracted from the LSM file, and the red, green and blue frames extracted, together with bright-field images. The cells were clearly visible on the bright-field images (Supplementary information, Figure S7). Some motion and deformation of cells during the sequence was observed. This motion was faster at the beginning of the sequence, slower towards the end. An algorithm was written to track specific locations on the cell throughout frames, allowing local average intensities to be obtained in a cell-relative manner.

Cell Selection and Region Selection: In the analysis, cells were selected that were not clumped together, reducing the probability of "cross-talk" in the captured color channels. Three locations were selected to act as the centers for sampling color channel intensity: a) on the boundary of cells (R1), b) $75 \%$ of the distance between the cell's center and boundary location (R2), and b) within the center of a cell (R3). The locations were selected to be easy to track, containing some spatial structure, and were placed manually by a naïve observer. The sampling of the intensities was performed by placing a $15 \times 15$ Gaussian-weighted window function centered at the selected locations. This was used to construct weighted intensity samples from the three regions sampled within each cell. The Gaussians were all unit normalized in integral.

Cell Region Tracking: Within individual cells, regions would deform over the sequence, making absolute image coordinates unreliable as locations for sampling the color signal 


\section{WILEY-VCH}

channels. Therefore, we developed and applied a region tracking algorithm to "follow" regions through frames. The region tracking used spatial patterns in smoothed versions of the light-field images, and was based on a pixel level algorithm that used patch cross-correlation. The patches were pre-filtered with either Gaussian or Laplacian of Gaussian functions (depending on the nature of the local bright field image structure), and tracking was verified by eye. If tracking failed, new locations were taken on the boundary to be tracked. The tracked region centroids were used as the centers for the Gaussian-weighted sampling regions.

Correlation of PI and ionic zinc inside and outside the cells: To assess the correlation between levels of Propidium iodide and ionic zinc, we calculated the absolute value of the correlation coefficient $(\rho)$ between the red (PI) and blue (Zinquin) signal levels. Signals were first normalized to the maximum value over the respective colour channels (red, green, blue) observed within the ten cells that were analysed. A bootstrap technique was used to estimate the probability distributions of the absolute value (unsigned) of the correlation coefficient, $\rho$, between red and blue signal levels, and then to evaluate the hypothesis that the levels of Propidium iodide and ionic zinc were strongly correlated $\left(\mathrm{H}_{1}\right)$. For each cell, 100 samples were drawn with replacement at random times from the blue and red channel signals within the centre of randomly selected (with replacement) cells. The correlation coefficient was calculated between these sample pairs. This process was repeated 10,000 times, to create an estimate of the distribution of $|\rho|$. Samples (again, 10,000, with replacement of cells and time samples) were also drawn from a surrogate null hypothesis $\left(\mathrm{H}_{0}\right)$ set of data that were obtained by randomly shuffling the time axis of observations. The distributions are displayed through the probability density plots for null hypothesis and under the hypothesis of strong correlation. The 20,000 correlation values are also summarized within a box plot, indicating median absolute correlation coefficient (red lines), 25th and 75th percentiles (box edges) and 


\section{WILEY-VCH}

approximately $99 \%$ coverage of the values of absolute correlation coefficient. Thus, the distributions of time-paired $\left(H_{1}\right)$ and unpaired $\left(H_{0}\right)$ distributions are very distinct. This suggests highly significant correlation (Kolmogorov-Smirnov statistic of 0.97) between ionic zinc levels and Propidium iodide concentrations from the same locations within cells. We tested image regions outside of cells for correlation between red and blue signals, to eliminate the possibility of correlation being present within the same images, but outside of cells. The same bootstrap test was performed on 8 regions outside of cells, including some with no visible structures within the regions, and others containing zinc particles. The same absolute correlation coefficient $(\rho)$ was calculated between time-shuffled and unshuffled data. There is no discernible difference in the distributions (KS-statistic of 0.03). This indicates that we can reject the hypothesis that the observed correlation between red and blue channels is in some way present within the imaging system: it clearly is to be found only within the cells.

Statistical analysis. All data were expressed as the mean \pm standard deviation of the values obtained from three replicates. Statistical analysis was carried out using a paired Student's $t$ test in all the viability assays. One way analysis of variance (ANOVA) was used to determine the statistical significance in the Annexin V/7AAD assay. The level of significance was accepted at $\mathrm{p} \leq 0.05$. The level of significance was indicated by the Asterisks: $* \mathrm{p}<=0.05$. The KS Statistic used for Figure 8 is a non-parametric test statistic that compares the shapes of two distributions to see if they are close or very far apart. Large values of KS statistic (close to 1) indicate very large differences in distribution. Small value (close to 0 ) indicates that two distributions are quite similar. The reference distributions representing the null hypothesis $\left(\mathrm{H}_{0}\right)$ are data of the same amplitude distributions as the raw data, but with randomized time axes. Therefore where the KS statistic is large, the data are strongly correlated in time $\left(\mathrm{H}_{1}\right)$; where the KS statistic is small, the data are uncorrelated in time. 


\section{WILEY-VCH}

\section{ACKNOWLEDGEMENTS}

A special thank you to Dr. Rachid Sougrat and Dr. Wei Zhu from the KAUST Imaging and Characterization Core lab for their immense expertise in confocal imaging and electron microscopy and also to Dr. Tahir F. Yapici from the KAUST Analytical Core lab for his skilled technical support. We also thank the members of the Cell Migration and Signaling lab at KAUST for their support.

\section{FUNDING}

This effort was supported by a King Abdullah University of Science and Technology Faculty Baseline Research Funding Program (BAS) to J.S.M. and was also supported by a Global Collaborative Research (AEA) Grant awarded to J.S.M., A.E.P. and M.R. A.E.P acknowledges funding from an Individual ERC starting grant (CNTBBB). The funders had no role in study design, data collection and analysis, decision to publish or preparation of the manuscript.

\section{COMPETING INTEREST}

No conflict of interest is declared. 
References

1. Holliday, D.L. and V. Speirs, Choosing the right cell line for breast cancer research. Breast Cancer Research, 2011. 13(4).

2. Brenton, J.D., et al., Molecular classification and molecular forecasting of breast cancer: Ready for clinical application? Journal of Clinical Oncology, 2005. 23(29): p. 7350-7360.

3. von Minckwitz, G. and M. Martin, Neoadjuvant treatments for triple-negative breast cancer (TNBC). Annals of Oncology, 2012. 23: p. 35-39.

4. Sirohi, B., et al., Platinum-based chemotherapy in triple-negative breast cancer. Annals of Oncology, 2008. 19(11): p. 1847-1852.

5. McNeil, S.E., Nanotechnology for the biologist. J Leukoc Biol, 2005. 78(3): p. 585-94.

6. Banerjee, H.N. and M. Verma, Application of nanotechnology in cancer. Technology in Cancer Research \& Treatment, 2008. 7(2): p. 149-54.

7. Nel, A.X., T. Madler, L. Li, N., Toxic potential of materials at the nanolevel. Science, 2006. 311(5761): p. 622-627.

8. Kishwar, S., et al., Intracellular ZnO Nanorods Conjugated with Protoporphyrin for Local Mediated Photochemistry and Efficient Treatment of Single Cancer Cell. Nanoscale Research Letters, 2010. 5(10): p. 1669-1674.

9. Zhang, H., et al., A strategy for ZnO nanorod mediated multi-mode cancer treatment. Biomaterials, 2011. 32(7): p. 1906-1914.

10. Mitra, S., et al., Porous $\mathrm{ZnO}$ nanorod for targeted delivery of doxorubicin: in vitro and in vivo response for therapeutic applications. Journal of Materials Chemistry, 2012. 22(45): p. 24145-24154.

11. Hong, H., et al., Cancer-targeted optical imaging with fluorescent zinc oxide nanowires. Nano Letters, 2011. 11(9): p. 3744-50.

12. Prasad, A.S., Zinc in human health: Effect of zinc on immune cells. Molecular Medicine, 2008. 14(5-6): p. 353-357.

13. Vallee, B.L. and D.S. Auld, Zinc coordination, function, and structure of zinc enzymes and other proteins. Biochemistry, 1990. 29(24): p. 5647-5659.

14. Dineley, K.E., T.V. Votyakova, and I.J. Reynolds, Zinc inhibition of cellular energy production: implications for mitochondria and neurodegeneration. Journal of Neurochemistry, 2003. 85(3): p. 563-570.

15. Franklin, R.B. and L.C. Costello, The Important Role of the Apoptotic Effects of Zinc in the Development of Cancers. Journal of Cellular Biochemistry, 2009. 106(5): p. 750-757.

16. Sasidharan, A., et al., Rapid dissolution of $\mathrm{ZnO}$ nanocrystals in acidic cancer microenvironment leading to preferential apoptosis. Nanoscale, 2011. 3(9): p. 3657-3669.

17. Sliwinski, T., et al., Zinc salts differentially modulate DNA damage in normal and cancer cells. Cell Biology International, 2009. 33(4): p. 542-547.

18. Hanley, C., et al., Preferential killing of cancer cells and activated human T cells using ZnO nanoparticles. Nanotechnology, 2008. 19(29).

19. Muller, K.H., et al., $\mathrm{pH}$-dependent toxicity of high aspect ratio $\mathrm{ZnO}$ nanowires in macrophages due to intracellular dissolution. ACS Nano, 2010. 4(11): p. 6767-79.

20. Rasmussen, J.W., et al., Zinc Oxide Nanoparticles for Selective Destruction of Tumor Cells and Potential for Drug Delivery Applications. Expert Opinion Drug Delivery, 2010. 7(9): p. 106377.

21. Tannock, I.F. and D. Rotin, Acid Ph in Tumors and Its Potential for Therapeutic Exploitation. Cancer Research, 1989. 49(16): p. 4373-4384.

22. David, C.A., et al., Dissolution Kinetics and Solubility of ZnO Nanoparticles Followed by AGNES. Journal of Physical Chemistry C, 2012. 116(21): p. 11758-11767.

23. Xia, T., et al., Comparison of the Mechanism of Toxicity of Zinc Oxide and Cerium Oxide Nanoparticles Based on Dissolution and Oxidative Stress Properties. ACS Nano, 2008. 2(10): p. 2121-2134. 


\section{WILEY-VCH}

24. Gilbert, B., et al., The Fate of ZnO Nanoparticles Administered to Human Bronchial Epithelial Cells. ACS Nano, 2012. 6(6): p. 4921-4930.

25. Gasparini, G., et al., Vascular integrin alpha(v)beta3: a new prognostic indicator in breast cancer. Clinical Cancer Research, 1998. 4(11): p. 2625-34.

26. Brooks, P.C., R.A.F. Clark, and D.A. Cheresh, Requirement of Vascular Integrin Alpha(V)Beta(3) for Angiogenesis. Science, 1994. 264(5158): p. 569-571.

27. Rathinam, R. and S.K. Alahari, Important role of integrins in the cancer biology. Cancer Metastasis Reviews, 2010. 29(1): p. 223-37.

28. Qamar, S., et al., Anticancer SAR models for MCF-7 and MDA-MB-231 breast cell lines. Anticancer research, 2011. 31(10): p. 3247-3252.

29. Boyd, M.R., The $\mathrm{NCl}$ in vitro anticancer drug discovery screen, in Anticancer Drug Development Guide. 1997, Springer. p. 23-42.

30. Monks, A., et al., Feasibility of a high-flux anticancer drug screen using a diverse panel of cultured human tumor cell lines. Journal of the National Cancer Institute, 1991. 83(11): p. 757-766.

31. Chen, S., et al., Avoiding artefacts during electron microscopy of silver nanomaterials exposed to biological environments. Journal of microscopy, 2015.

32. Mu, Q.S., et al., Systematic Investigation of the Physicochemical Factors That Contribute to the Toxicity of ZnO Nanoparticles. Chemical Research in Toxicology, 2014. 27(4): p. 558-567.

33. Zardavas, D., et al., Clinical management of breast cancer heterogeneity. Nature Reviews Clinical Oncology, 2015. 12(7): p. 381-94.

34. Qin, Y., et al., Measuring steady-state and dynamic endoplasmic reticulum and Golgi Zn(2+) with genetically encoded sensors. Proceedings of the National Academy of Sciences of the United States of America, 2011. 108(18): p. 7351-7356.

35. Rounds, C.M., et al., Propidium iodide competes with $\mathrm{Ca}(2+)$ to label pectin in pollen tubes and Arabidopsis root hairs. Plant Physiol, 2011. 157(1): p. 175-87.

36. Krzywinski, M. and N. Altman, Points of significance: Visualizing samples with box plots. Nature methods, 2014. 11(2): p. 119-120.

37. Cleator, S., W. Heller, and R.C. Coombes, Triple-negative breast cancer: therapeutic options. The Lancet Oncology, 2007. 8(3): p. 235-244.

38. Hudis, C.A. and L. Gianni, Triple-negative breast cancer: an unmet medical need. The oncologist, 2011. 16(Supplement 1): p. 1-11.

39. Akhtar, M.J., et al., Zinc oxide nanoparticles selectively induce apoptosis in human cancer cells through reactive oxygen species. International journal of nanomedicine, 2012. 7: p. 845.

40. Bacchetta, R., et al., Evidence and uptake routes for Zinc oxide nanoparticles through the gastrointestinal barrier in Xenopus laevis. Nanotoxicology, 2014. 8(7): p. 728-44.

41. Jingwen, S., et al., Microsomal Glutathione Transferase 1 Protects Against Toxicity Induced by Silica Nanoparticles but Not by Zinc Oxide Nanoparticles. ACS Nano, 2012.

42. Churchman, A.H., et al., Serum albumin enhances the membrane activity of ZnO nanoparticles. Chemical communications (Cambridge, England), 2013. 49(39): p. 4172-4174.

43. Muhammad, F., et al., pH-Triggered controlled drug release from mesoporous silica nanoparticles via intracelluar dissolution of $\mathrm{ZnO}$ nanolids. Journal of the American Chemical Society, 2011. 133(23): p. 8778-81.

44. Lin, W.S., et al., Toxicity of nano- and micro-sized ZnO particles in human lung epithelial cells. Journal of Nanoparticle Research, 2009. 11(1): p. 25-39.

45. Al-Hajj, M., et al., Therapeutic implications of cancer stem cells. Current Opinion in Genetics \& Development, 2004. 14(1): p. 43-47.

46. Selby, P., J.P. Bizzari, and R.N. Buick, Therapeutic implications of a stem cell model for human breast cancer: a hypothesis. Cancer Treatment Reports, 1983. 67(7-8): p. 659-63.

47. Greve, B., et al., Flow cytometry in cancer stem cell analysis and separation. Cytometry A, 2012. 81(4): p. 284-93. 


\section{WILEY-VCH}

48. Kakarala, M. and M.S. Wicha, Implications of the cancer stem-cell hypothesis for breast cancer prevention and therapy. Journal of Clinical Oncology, 2008. 26(17): p. 2813-2820.

49. Al-Hajj, M., et al., Prospective identification of tumorigenic breast cancer cells. PNAS, Proceedings of the National Academy of Sciences, 2003. 100(7): p. 3983-8.

50. Prat, A., et al., Phenotypic and molecular characterization of the claudin-low intrinsic subtype of breast cancer. Breast Cancer Research, 2010. 12(5).

51. Sheridan, C., et al., CD44(+)/CD24(-) breast cancer cells exhibit enhanced invasive properties: an early step necessary for metastasis. Breast Cancer Research, 2006. 8(5): p. 13.

52. Burdick, M.M., et al., Expression of E-selectin ligands on circulating tumor cells: crossregulation with cancer stem cell regulatory pathways? Frontiers in Oncology, 2012. 2: p. 103.

53. Danhier, F., A. Le Breton, and V. Preat, RGD-Based Strategies To Target Alpha(v) Beta(3) Integrin in Cancer Therapy and Diagnosis. Molecular Pharmaceutics, 2012. 9(11): p. 29612973.

54. Adam, N., et al., The chronic toxicity of $\mathrm{ZnO}$ nanoparticles and $\mathrm{ZnCl} 2$ to Daphnia magna and the use of different methods to assess nanoparticle aggregation and dissolution. Nanotoxicology, 2014. 8(7): p. 709-717.

55. Arap, W., R. Pasqualini, and E. Ruoslahti, Cancer treatment by targeted drug delivery to tumor vasculature in a mouse model. Science, 1998. 279(5349): p. 377-380.

56. Okochi, M., et al., Peptide array-based characterization and design of ZnO-high affinity peptides. Biotechnology Bioengineering, 2010. 106(6): p. 845-51.

57. Rampersad, S.N., Multiple Applications of Alamar Blue as an Indicator of Metabolic Function and Cellular Health in Cell Viability Bioassays. Sensors, 2012. 12(9): p. 12347-12360.

58. Holder, A.L., et al., Particle-induced artifacts in the MTT and LDH viability assays. Chemical Research in Toxicology, 2012. 25(9): p. 1885-92.

59. Kimura, Y., et al., Hydrogen sulfide protects HT22 neuronal cells from oxidative stress. Antioxidants \& Redox Signaling, 2006. 8(3-4): p. 661-670.

60. McDonald, K.L., Rapid embedding methods into epoxy and $L R$ White resins for morphological and immunological analysis of cryofixed biological specimens. Microscopy and microanalysis, 2014. 20(01): p. 152-163. 